\title{
Contribución al estudio de la toxoplasmosis experimental
}

\author{
por \\ Pedro Morera* y Giuseppe Barbareschi**
}

(Recibido para su publicación el 1 de setiembre de 1956)

En dos publicaciones anteriores, CéSPEDES y MORERA $(1,2)$ reportaron el hallazgo de los tres primeros casos de toxoplasmosis humana encontrados en Costa Rica.

Del segundo de estos casos, un niño de seis años proveniente del caserío la Esperanza, en la costa del Pacífico, se aisló una cepa de Toxoplasma gondii. Esta cepa se ha mantenido en el laboratorio mediante pasajes en ratones, bajo la denominación de "La Esperanza", en recuerdo del lugar de origen del paciente que hizo posible su aislamiento.

Con este material hemos hecho un estudio de las lesiones histopatológicas presentadas por los animales de laboratorio al ser inoculados con dosis controladas.

La mayoría de los trabajos experimentales se han llevado a cabo utilizando ratones blancos por ser éstos muy susceptibles; por otra parte se ha demostrado que el curso de la enfermedad en estos animales no es influenciado por la constitución genética (3), la edad ni el sexo (9).

Nosotros hemos usado ratones inoculados por vía intraperitoneal para el presente trabajo, ya que ésta junto con la intracerebral garantiza un ciento por ciento de prendimiento cuando se inoculan con un exudado rico en parásitos (9).

Además de ratones, hemos utilizado ratas blancas y cobayos para hacer un estudio comparativo.

* Departamento de Anatomía Patológica del Hospital San Juan de Dios.

Departamento de Histología Normal de la Facultad de Microbiología de la Universidad de Costa Rica.

** Departamento de Anatomía Patológica del Hospital San Juan de Dios. 


\section{MATERIAL Y METODOS}

Para la realización del presente estudio hemos utilizado lotes de cuatro animales de los que más comúnmente se usan, a saber: ratones, ratas y cobayos. Todos estos animales habían sido criados en el laboratorio durante varias generaciones, lo cual es de mucha importancia para descartar la posibilidad de que hubiera en ellos una infección latente toxoplásmica.

El material de inoculación lo constituyó un exudado peritoneal de ratones infectados con una cepa de Toxoplasma gondii, aislada de uno de nuestros casos humanos en diciembre de 1954 y mantenida mediante pasajes en ratones hasta la fecha, con el nombre de "La Esperanza". Esta cepa está en la actualidad perfectamente estabilizada en su patogenicidad para los ratones, de modo que determina su muerte regularmente cada seis días.

Efectuado un recuento del exudado peritoneal de los ratones destinados a la conservación de la cepa, por medio de una cámara de Levy, se determinó que contenía 8.000.000 de parásitos por centímetro cúbico; este número corresponde tanto a formas libres como a las endocelulares, que también fueron contadas contrastando fuertemente la preparación. El exudado se diluyó $1: 8$ con solución salina estéril para tener una concentración final de 100.000 parásitos por $0,1 \mathrm{cc}$.

Las inoculaciones se hicieron dividiendo los animales en tres lotes de la siguiente manera:

Lote No 1:

Cuatro ratones blancos, de $18 \mathrm{gm}$. de peso, inoculados por vía intraperitoneal con 100.000 parásitos el 20-III-56, muriendo todos ellos el 26-III-56.

Lote No 2:

Cuatro cobayos (Cavia cobaya) inoculados por vía intraperitoneal con 300.000 parásitos el 20-III-56. El 26-III-56 es decir seis días después murieron los dos primeros y los otros dos fueron sacrificados el 16-V-56.

Lole No 3:

Cuatro ratas blancas inoculadas por vía intraperitoneal con 200.000 parásitos el 20-III-56. El 11-IV-1956 fueron sacrificadas las dos primeras del lote y el 16-V-56 las dos restantes.

A todos los animales se les practicó la autopsia y sus órganos fueron fijados en formol al $10 \%$ para efectuar el estudio histológico. Las piezas fijadas se incluyeron en parafina y los cortes así obtenidos fueron teñidos por el método de hematoxilina-easina (cit. en Romeis (8) ) y otras técnicas especiales para me. jor observación de los parásitos y los tejidos, tales como tricrómico de Gallego (cit. en Langeron (5) ) y Laidlaw (cit. en Lillie (6) ). 


\section{RESULTADOS}

\section{LOTE $N^{\circ} 1$}

Los cuatro ratones blancos que componen este lote murieron al sexto día de la inoculación presentando todos ellos lesiones similares, tales como exudado seroso en la cavidad abdominal con gran cantidad de parásitos (fig. 1) y una ligera cianosis del hígado y del bazo.

\section{Examen Histológico}

RIÑÓN

\section{Caso No 1:}

Los glomérulos presentan una marcada congestión; a veces se encuentra importante congestión de la arteriola aferente, rodeada de un infiltrado linfomonocitario (fig. 2). La cápsula de Bowman presenta tumefacción de las células sin duplicación epitelial. En algunos glomérulos la membrana basal de los capilares intraglomerulares tienen un aspecto hialino con tendencia a la coalescencia. Los túbulos contorneados presentan un aspecto microgranular y a veces vacuolizado, que llega hasta la necrosis de las células, con aspecto de metamorfosis albuminoidea o grasa. Los núcleos a veces son vesiculares con cromatina esparcida, a veces picnóticos y otras veces muestran desintegración granular; hay también notable congestión de los capilares con hemorragia y depósitos de hemosiderina granular entre los túbulos. Congestión de la arteriola y de las venas rectas. En la medular se encuentran muchos cilindros hialinos granulosos y epiteliales pero no hay cilindros hemáticos. Las células de los túbulos rectos presentan también metamorfosis albuminoidea pero de grado moderado. En algunas regiones de la cápsula renal se observan grandes cantidades de parásitos (fig. 3).

Diagnóstico: Nefrosis tóxica de tipo albuminoideo adiposo que llega hasta la necrosis. Congestión e infiltración preglomerular. Toxoplasmosis.

\section{Caso No 2:}

Los glomérulos tienen una moderada homogeneización del mesoangio con aspecto de conglutinación de las asas capilares de la red glomerular. La cápsula de Bowman es normal; la arteriola aferente presenta notable dilatación y tumefacción dẹ endotelio; en los alrededores hay infiltrado linfomonocitario (fig. 4 ), pero no se encuentran polimorfonucleares. Los túbulos contorneados presentan un cuadro de tipo albuminoideo grasoso; tanto en ellos como en las porciones rectas del asa de Henle se encuentran pseudoquistes llenos de parásitos (fig. 5).

Diagnóstico: Periarteriolitis preglomerular con conglutinación de las asas. Congestión preglomerular. Toxoplasmosis. 


\section{Caso No 3:}

En algunos glomérulos se encuentran pseudoquistes (figs. 6 y 7 ) y una moderada proliferación de las células del mesoangio y del endotelio capilar dando un cuadro de hipernucleosis con relativa isquemia glomerular. También en los túbulos contorneados se encuentran muchos pseudoquistes (fig. 8) que a la coloración con carbonato de plata presentan una membrana bien definida (fig. 9). El epitelio de la cápsula de Bowman es tumefacto; en algunos puntos se observa congestión de las arteriolas aferentes. Alrededor de los vasos medios se encuentra un proceso inflamatorio adventicial con células de tipo linfoplasmocelular y una endoteliosis a células endoteliales tumefactas. Los túbulos contorneados presentan metamorfosis albuminoidea. La parte medular revela un proceso patósico moderado a nivel de los túbulos rectos. Los vasos rectos medulares presentan congestión.

Diagnóstico: Glomerulitis con isquemia glomerular inicial. Endoteliosis de los vasos medios y pequeños con infiltrado inflamatorio adventicial. Metamorfosis albuminoidea tubular. Congestión. Toxoplasmosis.

\section{Caso No 4:}

La cortical presenta glomérulos aparentemente normales; a nivel de la arteriola aferente hay un proceso congestivo con dilatación de la misma e infiltrado periarteriolar de tipo linfoplasmocelular (fig. 10). Los túbulos contorneados de primer orden presentan un proceso metamorfósico de tipo albuminoideo vacuolar. En el lumen se encuentran algunas células en las cuales se observa un núcleo pálido y citoplasma lleno de parásitos (fig. 11). En los cortes coloreados con carbonato de plata estos pseudoquistes aparecen rodeados por una membrana bien definida coloreada en negro (figs. 12 y 13). En los túbulos contorneados de segundo orden, en el asa de Henle y en los túbulos colectores hay procesos metamorfósicơs y células cargadas de parásitos en el lumen. En el intersticio hay infiltrados linfocitarios bastante difusos. La medular presenta una moderada congestión de los vasos rectos, algunos cilindros hialinos, moderado infiltrado linfocitario y a veces dilatación tubular con una tenue sustancia proteica en el lumen.

Diagnóstico: Nefrosis albuminoidea adiposa de los túbulos contorneados de primero y segundo orden y parte ascendente del asa de Henle. Congestión preglomerular con infiltración linfoplasmocelular periarteriolar. Congestión medular. Toxoplasmosis.

BAZO

Caso No 1 :

La pulpa blanca se encuentra en hiperactividad tanto en la línea linfocitaria como retículoendotelial. Los vasos centrolobulillares se presentan tumefactos. La pulpa roja presenta una extrema congestión con grandes hemorragias, mucho pigmento hemosiderínico y zonas violentas de necrosis (fig. 14) con 
exudado fibrinoso corpusculado y considerable cantidad de detritos celulares amorfos en actividad macrofágica. Algunos macrófagos aparecen con su interior totalmente ocupado por parásitos.

Diagnóstico: Esplenitis aguda necrótica hemorrágica con endoteliosis centrolobular. Toxoplasmosis.

\section{Caso N? 2:}

La pulpa blanca aparece disminuida y la arteriola centro-folicular presenta tumefacción endotelial; la cantidad de linfocitos está relativamente aumentada; en la pulpa roja se nota un aumento considerable de las células reticulares con un componente plasmocelular bastante evidente que rodea zonas de necrosis. En la vecindad de estas zonas de necrosis se encuentran algunos macrófagos llenos de toxoplasmas (fig. 15). No hay hemorragia.

Diagnóstico: Necrosis focal con granuloma reactivo retículo-plasmocelular. Hipoplasia de la pulpa blanca. Toxoplasmosis.

\section{Caso No 3:}

Se observa un tejido de granulación formado por células con citoplasma grande eosinófilo, núcleo grande con cromatina difusa, que se parecen mucho a células retículo-histiocitarias activadas. En este tejido de granulación se encuentran también zonas de necrosis granular acidófila y muchas células cargadas de hemosiderina; también se observan gran cantidad de parásitos en células retículo-histiocitarias (fig. 16); no se encuentran toxoplasmas en las zonas de necrosis. Los vasos esplénicos presentan tumefacción del endotelio. Los folículos linfáticos se presentan deformados, en vías de sustitución por tejido de granulación.

Diagnóstico: Retículoendotelitis granulomatosa difusa con focos de necrosis. Hipoplasia de la pulpa blanca. Toxoplasmosis.

\section{Caso No 4:}

Presenta una difusa hiperplasia reticular con zonas de necrosis de aspecto granular acidófilo (fig. 17); hay también miuchas células cargadas de hemosiderina y una congestión difusa; en las zonas necróticas y en células fuera de ellas se encuentran gran cantidad de parásitos (fig. 18).

Diagnóstico: Esplenitis con hiperplasia retículoendotelial y necrosis con actividad macrofágica toxoplásmica.

HÍGADO

\section{Caso № 1:}

El parénquima hepático presenta alteraciones difusas de tipo albuminoideo microvacuolar en el citoplasma, a veces de tipo adiposo (fig. 19); se encuentran además numerosas zonas de necrosis tanto en el lobulillo como en los espacios portales; la necrosis es de tipo desintegrativo total con residuo granular de tipo cro- 
matínico y coagulación citoplasmática. En los alrededores de los vasos se encuentra infiltración linfocitaria difusa, macrófagos con parásitos (figs. 20 y 21), y congestión arteriosa y capilar. En el espesor de la cápsula de Glisson hay gran cantidad de parásitos (fig. 22).

Diagnóstico: Hepatosis albuminoidea con necrosis focales. Infiltración perivascular. Congestión. Toxoplasmosis.

\section{Caso No 2:}

Las células hepáticas presentan metamorfosis albuminoidea, a veces con vacuolización. Se encuentran también numerosas células de tipo linfocitario con algunos histiocitos y monocitos. En los espacios portz hay zonas de congestión (fig. 23). En la cápsula de Glisson y en las células retículoendoteliales se encuentran gran cantidad de toxoplasmas (figs. 24 y 25 ).

Diagnóstico: Hepatitis linfomonocitaria con componente hepatósico de tipo albuminoideo. Toxoplasmosis.

\section{Caso No 3:}

Alrededor de los vasos portales y arteriolares se encuentran numerosos focos inflamatorios de tipo microgranulomatoso; también hay un infiltrado difuso entre las células hepáticas y algunos focos necróticos (fig. 26) en los cuales hay también edema, y en esos casos, gran cantidad de parásitos. En el límite de los lóbulos hepáticos se ha acumulado una gran cantidad de fibrina, en cuyas redes se pueden apreciar enormes cantidades de parásitos (figs. 27 y 28). Las células hepáticas son muy vacuolizadas, con aspecto de metamorfosis albuminoidea adiposa inicial. La cápsula de Glisson es muy edematosa y contiene en su espesor gran cantidad de toxoplasmas. Hay también congestión arteriolar y capilar.

Diagnóstico: Hepatitis aguda, a veces con necrosis focal. Metamorfosis albuminoidea adiposa de las células hepáticas. Toxoplasmosis.

\section{Caso N: 4:}

Los hepatones presentan células con metamorfosis vacuolar; los núcleos de las células son muy polimorfos por procesos de metamorfosis nuclear. En el intersticio hay infiltración linfocitaria difusa; en la parte subcapsular y capsular, los parásitos son muy abundantes, presentándose además focos de necrosis grave del parénquima hepático en las cuales se observan algunos parásitos (fig. 29).

Diagnóstico: Hepatosis adipo-necrótica, a veces hemorrágica. Infiltración intersticial linfocitaria. Toxoplasmosis.

\section{MIOCARDIO}

\section{Caso No 1:}

Edema generalizado; algunas células miocárdicas presentan un citoplasma más eosinófilo, con aspecto homogéneo no pudiéndose evidenciar los campos de Conheim que se observan en las fibras normales. 
Diagnóstico: Necrobiosis celular con homogeneización de tipo coagulativo. Toxicosis grave de la fibra miocárdica.

\section{Caso No 2:}

Se encuentran zonas de homogeneización citoplasmática e intensa acidofilia; algunos núcleos paracen metamorfósicos, si bien no llegan a la picnosis.

Diagnóstico: Miocardosis tóxica parcelar.

\section{Caso No 3:}

Infiltración difusa y microgranulomatosa con metamorfosis albuminoidea de algunas fibras miocárdicas cuyo citoplasma es a veces homogéneo (fig. 30).

Diagnóstico: Miocarditis, a veces microgranulomatosa, con miocardosis albuminoidea.

\section{Caso No 4:}

El dibujo miofibrilar es normal, pero hay un moderado edema intersticial. Algunas miofibrillas son eosinófilas como en los procesos de gelificación proteica.

Diagnóstico: Edema y miocardosis.

\section{PULMÓN}

Caso No 1:

Congestión de los vasos arteriosos; zonas de atelectasia.

\section{Caso No 2:}

El tejido pulmonar se encuentra congestionado sobre todo a nivel de los capilares interalveolares y las arteriolas interlobulares (fig. 31). En una arteria se encontró un coágulo blanco, parecido a un coágulo preagónico.

\section{Caso N: 3:}

Moderada congestión de los capilares septales e infiltrado inflamatorio alrededor de los linfáticos peribronquiales (fig. 32).

\section{Caso No 4 :}

Congestión interalveolar.

\section{Cerebro}

Sólo en el primero y segundo caso se presentó un moderado edema, siendo normal en los dos últimos. 
nera: los dos primeros, seis dias después de inoculados, presentando gran cantidad de exudado seroso en la cavidad peritoneal, perihepatitis fibrinosa leve y ligera cianosis de las vísceras abdominales. Los dos cobayos restantes fueron sacrificados en la cámara de gases 56 días después de inoculados, no observándose en ellos lesiones macroscópicas.

\section{Examen bistológico}

\section{RIÑóN}

\section{Caso No 1:}

La cortical presenta alrededor de los glomérulos y de los túbulos contorneados, pero sobre todo alrededor de las arteriolas aferentes y los vasos de mayor calibre, infiltración de elementos de tipo linfo-histiocitario. A nivel de los glomérulos se observa un moderado espesamiento de la membrana basal capilar y congestión asociada a discreto aumento de los elementos de tipo endotelial monocítico. El epitelio de los túbulos presenta intensa vacuolización y granulosidad con reducción del lumen, en algunos casos con desaparecimiento del núcleo. En el lumen de los túbulos del nefrón distal hay material albuminoideo de tipo hialino microgranuloso (fig. 33). En la pared de la cápsula renal se encuentran algunos parásitos (fig. 34).

Diagnóstico: Nefritis intersticial microgranulomatosa. Probable glomerulosis membranosa inicial. Túbulonef rosis albuminoidea vacuolar. Cilindruria masiva. Toxoplasmosis.

\section{Caso No 2:}

En la cortical se puede observar apreciable congestión arteriolar, sobre todo de las arterias interlobulares (fig. 35) a nivel de la arteriola aferente alrededor de las cuales hay precipitaciones de hemosiderina granular. Los túbulos contorneados de primer orden presentan túbulo-necrosis de tipo tóxico, es decir, con conservación de la membrana basal, pero con metamorfosis albuminoidea grasosa; el lumen está estrechado y hay detritos amorfos proteicos. En los glomérulos se aprecia una moderada reacción proliferativa de tipo endotelial e histiocitario con moderada isquemia glomerular. La membrana basal de los capilares glomerulares es ligeramente más evidente en algunos casos; las células endoteliales en algunos glomérulos son tumefactas y edematosas con un gran núcleo vesiculoso de tipo endotelioblasto. En las células epiteliales de la cápsula de Bowman hay cierto grado de tumefacción; otros glomérulos al contrario, presentan tumefacción de la red mirabilis. En algunos glomérulos se observan gránulos de hemosiderina amorfa.

Diagnóstico: Glomerulitis proliferativa inicial. Túbulonefrosis lipoproteica de mecanismo tóxico. Congestión de las arteriolas interlobulares y aferentes. Tesaurosis pigmentaria hemosiderínica. 


\section{Caso No 3:}

En la cortical, a nivel del nefrón proximal, se encuentra una túbulonefrosis albuminoidea adiposa con dilatación micronef rohidrósica. Los glomérulos presentan una proliferación parcelar de los endotelios y de los histiocitos con relativa isquemia (forma intracapilar de la glomerulitis proliferativa); a veces se observa reducción del glomérulo con aumento relativo de la cápsula de Bowman, en la cual hay una moderada reacción inflamatoria. En algunos glomérulos se observan sinequias glomérulo-capsulares y tendencia a la lobulación (fig. 36). La arteria aferente presenta hiperplasia y tumefacción endotelial. Aun se observan signos de una glomerulitis proliferativa intercapilar con deformación más o menos evidente del glomérulo; en algunos de ellos se observa engrosamiento y homogeneización de la membrana basal. La parte medular presenta hipotrofia de las células tubulares; nef rón proximal con aspecto de isquemia crónica. En el intersticio se nota un aumento de las células histiocitarias.

Diagnóstico: Glomerulitis proliferativa subaguda intracapilar. Túbulonefrosis metamorfósica lipoproteica del nefrón proximal. Hipotrofia con micronefrohidrosis del nefrón distal. Infiltrado microgranulomatoso intersticial.

\section{Caso N: 4:}

En la cortical se observan los túbulos del nefrón proximal con nefrosis de tipo albuminoideo, estrechamiento del lumen y citoplasma granuloso de grado moderado. Hay dilatación tanto de las arteriolas interlobulares como de las aferentes. Los glomérulos presentan una hiperplasia endotelial intraglomerular con isquemia relativa, moderada lobulación de las asas y reducción de volumen; algunos de ellos presentan sinequias glomérulo-capsulares con reacción proliferativa en la hoja parietal de la cápsula de Bowman. En la parte medular, los túbulos son dilatados e hipotróficos con congestión de la red arteriosa peritubular.

Diagnóstico: Glomerulitis subaguda intracapilar y a veces extracapilar con túbulonefrosis metamorfósica albuminoidea del nefrón proximal. Hipotrofia y dilatación del nefrón distal.

BAZO

\section{Caso No 1:}

Aumento difuso del retículo con hipoplasia del componente linfocitario. En la médula roja se encuentran algunos pseudoquistes cuyo interior está lleno de toxoplasmas (figs. 37 y 38 ).

Diagnóstico: Hiperplasia reticular difusa. Toxoplasmosis.

\section{Caso No 2:}

A nivel de la pulpa roja se aprecia una importante proliferación retículoendotelial con zonas focales de tipo granulomatoso necrótico. La hemosiderina es muy abundante. La pulpa blanca presenta hiperplasia reticular, escasos linfo- 
citos pero so hay necrosis; ocasionalmente se encuentran pseudoquistes en esta zona (fig. 2?).

Diagnóstico: Esplenitis granulomatosa necrótica de tipo retículoendotelitis granulomatosa. Toxoplasmosis.

\section{Caso No 3:}

En la pulpa blanca se observa un aumento notable de células reticulares y fibroblastos, con tendencia a la formación de granulomas cicatriciales; hemosiderina muy abundante (fig. 40); los corpúsculos de Malpighi presentan también un aumento notable del retículo con tendencia a la formación granulomatosa crónica con evolución inicial fibroblástica.

Diagnóstico: Esplenitis granulomatosa en evolución cicatricial.

\section{Caso No 4:}

La pulpa blanca presenta aumento notable del retículo y algunas zonas de necrosis; a veces se observan algunos fibroblastos; a nivel de los corpúsculos de Malpighi hay aumento de la pulpa blanca con tendencia a asumir formas alargadas de tipo fibroblástico. Importante es el depósito de hemosiderina en los macrófagos.

Diagnóstico: Esplenitis granulomatosa, parcialmente necrótica y cicatricial.

\section{HíGADO}

\section{Caso № 1:}

Lobulillos un poco borrosos con citoplasma celular moderadamente turbio. Intersticio portal y centrolobulillar con infiltrado microgranulomatoso linfo-histiocitario. En la zona sub-capsular el infiltrado es más intenso observándose en algunas partes zonas que evolucionan hacia la necrosis (fig. 41); la cápsula de Glisson y algunas zonas subcapsulares están muy infiltradas por toxoplasmas.

Diagnóstico: Hepatitis intersticial granulomatosa. Toxoplasmosis.

\section{Caso No 2:}

El dibujo lobulillar generalmente está conservado, pero en los espacios portales y también en las trabéculas se encuentran infiltrados linfocitarios con notable congestión de la vena centrolobulillar. Las células hepáticas presentan cierto grado de metamorfosis, aparentemente albuminoidea. En algunos lugares hay necrosis celular. A nivel del espacio subcapsular los fenómenos necróticos son más evidentes, con alteración de la estructura lobulillar, habiendo además numerosas células hepáticas con homogeneización citoplasmática acidófila, picnosis nuclear y cariorrexis; en esta zona hay gran cantidad de parásitos (fig. 42).

Diagnóstico: Hepatosis de tipo metamorfósico a!buminoideo con necrosis parcelar. Infiltración linfocitaria. Congestión y edema. Toxoplasmosis. . 
proteicas, por lo cual el citoplasma es granuloso vacuolizado y se tiñe mal; en la red capilar se aprecia notable congestión con evidenciación de las células de Kupffer que aparecen en gran cantidad. Congestión intensa de los vasos arteriosos.

Diagnóstico: Hepatosis metamorfósica lipoproteica con evidenciación de la red capilar y de las células de Kupffer. Congestión.

\section{Caso No 4:}

Dibujo lobulillar un poco confuso con congestión arteriolocapilar y un tenue infiltrado linfocitario. Algunas arteriolas presentan pared hialinizada e hiperplasia endotelial con células tumefactas y anchas.

Las células hepáticas presentan varios grados de metamorfosis. En algunos espacios de Kiernan, sobre todo alrededor de las arteriolas, hay granulomas de tipo histiocitario reticular.

Diagnóstico: Hepatitis intersticial granulomatosa. Granulomatosis retículohistiocitaria perivascular con hepatosis metamorfósica albuminoidea difusa. Congestión. Hialinosis arteriolar.

\section{MIOCARDIO}

\section{Caso No 1:}

Pequeños infiltrados perivasculares e intersticiales de tipo linfo-histiocitaric. Algunas células miocárdicas presentan metamorfosis albuminoidea de tipo coagulativo con hiper-eosinofilia.

Diagnóstico: Miocarditis microgranulomatosa con miocardosis albuminoidea parcelar.

\section{Caso No 2:}

Edema de las fibras con aspecto granuloso de las miofibrillas. Se encuentran algunas células con el citoplasma homogéneo y eosinófilo. Infiltrado linfocitario difuso.

Diagnóstico: Miocardosis albuminoidea con pequeñas zonas de homogeneización eosinofílica; miocarditis linfocitaria difusa concomitante.

\section{Caso № 3:}

Edema de las fibras con disminución de la estriación transversal y longitudinal.

Caso No 4:

Congestión de los vasos y edema intersticial; las fibras presentan la estriación un poco borrosa.

\section{PULMÓN}

\section{Caso No 1:}

Moderada congestión interalveolar. Hay una zona en la cual hay pequeños focos alveolíticos con infiltrado periarteriolar, interalveolar e intraalveolar. 
Diagnóstico: Pequeños focos de bronconeumonía hemorrágica no purulenta.

\section{Caso No 2:}

El parénquima pulmonar presenta congestión total y focos de bronconeumonitis hemorrágica con exudado endoalveolar formado en su mayor parte por glóbulos rojos, y en algunos lugares por histiocitos (alveolitis histiocitaria). Alrededor de los vasos, arteriolas y capilares, hay violenta proliferación de elementos histiales (histiocitos, algunas células plasmáticas y numerosos eosinófilos). En los espacios interalveolares hay algunos macrófagos que contienen toxoplasmas (fig. 43). Hay además congestión interalveolar y edema.

Diagnóstico: Alveolitis parcelar. Broncoalveolitis hemorrágica histiocitaria. Arteriolitis granulomatosa. Congestión y edema. Toxoplasmosis.

\section{Caso No 3:}

Congestión total del parénquima con hemosiderosis interalveolar. El cuadro más evidente está representado por un infiltrado de tipo granulomatoso con fibroblastos alrededor de los vasos, que llega a veces a la adventicia y a la túnica media de los más pequeños, en los cuales hay en ocasiones pequeñas trombosis.

Diagnóstico: Peri-meso-endoarteritis granulomatosa con microtrombosis. Congestión.

\section{Caso No 4:}

El parénquima pulmonar presenta congestión generalizada, pero sobre todo fenómenos arteríticos que se presentan en forma de una periarteritis tífica o bien granulomatosa, llegándose hasta obtener un cuadro de esclería arteriosa obliterante de tipo fibrohialino.

Diagnóstico: Periarteritis granulomatosa retículo-histiocitaria que llega hasta la esclería arteriosa obliterante. Congestión.

\section{Sistema NERVIOSO CENTRAL}

Del tejido nervioso se examinaron en este lote el cerebro y el cerebelo, no encontrándose en ningún caso lesiones de importancia.

\section{LOTE $\mathrm{N}^{2} 3$}

Las cuatro ratas blancas que componen este lote fueron sacrificadas de la siguiente manera: las dos primeras se colocaron en la cámara de gases 22 días después de la inoculación, no encontrándose en la autopsia lesiones de importancia. Las dos restantes se sacrificaron 56 días después de la inoculación, encontrándose en el caso $\mathrm{N}$. 4 los pulmones ocupados en su tercera parte por pequeños abscesos en cuyo interior se notó la presencia de exudado purulento cremoso (fig. 44). En el borde de uno de los lóbulos hepáticos de este mismo 
caso se encontró un quiste de $4 \mathrm{~mm}$. de diámetro identificado posteriormente como Cjisticercus fasciolaris.

\section{Examen Histológico}

RIÑÓN

\section{Caso No 1:}

La cortical presenta los túbulos del nefrón proximal con metamorfosis lipoproteica, estrechamiento y presencia de material granuloso en el lumen. Los glomérulos presentan tendencia a la lobulación con moderada hipernucleosis histial y relativa isquemia; en algunos lugares se observa reducción del volumen glomerular y periglomerulitis histiocitaria alrededor de la cápsula de Bowman, cuyas hojas, parietal y visceral presentan edema celular con ensanchamiento y tendencia a la proliferación. Congestión de la arteriola aferente de grado moderado. Dilatación con discreta hipotrofia tubular de la nefrona distal.

Diagnóstico: Glomerulitis proliferativa intracapilar. Túbulonef rosis lipoproteica. Congestión preglomerular.

\section{Caso No 2:}

Túbulonefrosis cortical del nefrón proximal; hialinosis de algunas arteriolas interlobulares; algunos glomérulos presentan congestión con moderado espesamiento de la membrana basal capilar y tendencia proliferativa de los endotelios y del mesoangio. En algunos glomérulos se observan sinequias glomérulo-capsulares muy evidentes. Congestión generalizada sin localización preglomerular importante. En algunos casos la membrana basal de la cápsula de Bowman es bastante evidente presentado homogeneización y espesamiento.

Diagnóstico: Glomerulosis de tipo membranoso con moderada proliferación endotelial. Túbulonef rosis lipoproteica.

\section{Caso N? 3:}

La cortical presenta túbulonefrosis albuminoidea con estrechez del lumen y presencia de material granular en el interior del mismo. Congestión de las arteriolas interlobulares y aferentes. Los glomérulos presentan hipernucleosis de grado moderado con engrosamiento y homogeneización de la cápsula de Bowman. Hay tendencia a la hialinosis de las paredes arteriolares con depósitos intraparietales de hemosiderina granular. La parte medular presenta hipotrofia con dilatación tubular.

Diagnóstico: Túbulonef rosis albuminoidea con moderada glomerulitis proliferativa. Hialinosis y congestión arteriolar.

\section{Caso No 4:}

Túbulonefrosis proximal moderada en la cortical. Congestión intersticial y glomerular muy intensa. Cilindros hialino-granulosos en la nef rona distal. He- 
mosiderosis generalizada. Hialinosis de las arteriolas interlobulares con trombosis.

Diagnóstico: Túbulonefrosis de mecanismo tóxico. Congestión.

BAzo

\section{Caso No 1:}

La pulpa roja presenta hiperplasia reticular con algunas zonas hemorrágicas. Los macrófagos presentan en el citoplasma hemosiderosis granular amorfa. Existen algunas zonas de necrosis en las que no se observan macrófagos con hemosiderina. Los folículos linfáticos presentan hiperplasia de los elementos linforreticulares.

Diagnóstico: Esplenitis granulomatosa retículo-histiocitaria hemorrágica. Hemosiderosis.

\section{Caso No 2:}

Hiperplasia reticular importante de la pulpa roja con congestión intensa pero sin hemosiderosis. Hipotrofia de los folículos linfáticos.

Diagnóstico: Esplenitis reticular granulomatosa.

\section{Caso No 3:}

La pulpa roja presenta hiperplasia reticular y pequeñas cicatrices de tipo fibroblástico fibrocitario. Hipotrofia de la pulpa blanca.

Diagnóstico: Esplenitis crónica granulomatosa.

\section{Caso No 4:}

Hiperplasia reticular de la pulpa roja, congestión y hemosiderosis. Hay también hiperplasia reticular de los folículos linfáticos con hialinosis de la arteriola centrolobulillar.

Diagnóstico: Esplenitis subaguda granulomatosa reticular.

HíGADO

\section{Caso No 1:}

Intensa congestión arteriosa y capilar en las trabéculas con hipotrofia y metamorfosis de tipo albuminoideo de las células hepáticas; existe además un infiltrado difuso de linfocitos. El dibujo lobulillar no está perdido.

Diagnóstico: Hepatosis albuminoidea. Infiltración linfocitaria difusa. Congestión.

\section{Caso No 2:}

Congestión arteriolo-capilar intensa con infiltración linfocitaria difusa $y$ hemosiderosis generalizada. Las células hepáticas presentan metamorfosis albu- 
minoideo-adiposa que llega hasta la necrosis en las zonas subcapsulares.

Diagnóstico: Hepatosis grave lipoproteica. Infiltración linfocitaria difusa. Çongestión.

\section{Caso Nọ 3:}

Dibujo lobulillar conservado. Congestión intensa arteriolo-capilar. Las células hepáticas presentan una moderada metamorfosis albuminoidea que llega hasta la necrosis en la zona subcapsular, en donde hay zonas de homogeneización eosinófila con fragmentos nucleares esparcidos.

Diagnóstico: Hepatosis lipoproteica con necrosis focal subcapsular. Congestión.

\section{Caso No 4:}

Congestión grave arteriolo-capilar con metamorfosis albuminoidea de las células hepáticas. Pequeños infiltrados linfocitarios perivasculares. En uno de los vértices del corte se aprecia una cavidad quística conteniendo un parásito identificado como Cysticercus fasciolaris (figs. 45 y 46).

Diagnóstico: Hepatosis albuminoidea. Congestión.

\section{Miocardio}

\section{Caso No 1:}

Las miofibrillas presentan el citoplasma un poco homogeneizado y discrómico. Probable miocardosis albuminoidea.

\section{Caso No 2:}

Miocardio edematoso.

\section{Caso No 3:}

Tendencia a la homogeneización de las células miocárdicas y pérdida de la estriación. Miocardosis.

\section{Caso No 4:}

Infiltración linfocitaria difusa. Metamorfosis albuminoidea citoplasmática con desaparición de la estriación transversal. Congestión y hialinosis de las arterias de calibre mediano.

Diagnóstico: Miocardosis albuminoidea con hialinosis arterial. Infiltración linfocitaria difusa.

\section{PULMÓN}

Caso $\mathrm{N}^{\circ}$ 1:

Pequeños focos inflamatorios en algunos de los tabiques interalveolares. 


\section{Caso No 2:}

En algunos tabiques interalveolares 'se encuentran pequeños focos inflamatorios formados por elementos mononucleares.

\section{Caso No 3:}

Sin lesiones.

\section{Caso No 4:}

A nivel del bronquio se aprecia un exudado formado por elementos polinucleares (fig. 47), alrededor del cual hay algunas formaciones granulomatosas en las que también se aprecia formación purulenta. Alrededor de los abscesos hay un tejido de granulación formado por histiocitos, plasmacélulas y reticulocitos mezclados con polinucleares y gran cantidad de células espumosas histiocitarias (fig. 48). En otros lugares hay granulomas sin fluidificación purulenta pero con tejido granulomatoso retículoendotelial; se observan también algunos polimorfonucleares. Los granulomas tienen una disposición en el parénquima muy similar a tubérculos miliares.

Diagnóstico: Neumonitis granulomatosa de tipo miliar peribronquial con abscesos dentro de algunos de los granulomas.

\section{Sistema NeRVioso CENTRAL}

El cerebro y el cerebelo fueron examinados histológicamente en cada una de las ratas que forman este grupo, no encontrándose en ningún caso alteraciones.

\section{COMENTARIO Y CONCLUSIONES}

En primer lugar, queremos destacar el hecho de que no todos los animales inoculados murieron a causa de la enfermedad, sino que algunos de ellos fueron sacrificados, lo cual no significa que posteriormente no pudieran haber muerto de toxoplasmosis.

En el lote No 1, los cuatro ratones blancos inoculados con 100.000 parásitos, murieron casi simultáneamente al sexto día, hecho que habíamos observado regularmente durante más de un año en el mantenimiento de nuestra cepa en el laboratorio; es curioso que, a pesar de haber rebajado la dosis inoculada desde 8.000.000 aproximadamente, hasta 100.000 toxoplasmas, la muerte se presentó en el mismo plazo; por otra parte, las lesiones observadas en la autopsia eran las mismas que las presentadas por los ratones utilizados en la conservación de la cepa, es decir, exudado peritoneal serofibrinoso muy rico en parásitos y cianosis de las vísceras abdominales; esta observación nos ha hecho pensar que en límites altos, las diferencias de dosis no tienen gran efecto en el curso de la enfermedad. 
En el lote No 2, dos cobayos murieron, al igual que los ratones, al sexto día después de la inoculación, presentando también cianosis de las vísceras abdominales y exudado seroso; este exudado es probablemente muy rico en fibrinógeno ya que alrededor del hígado de los cobayos se organizó una pequeña red de fibrina, dando un cuadro de perihepatitis.

Estos seis animales que hemos mencionado, los consideramos como casos agudos; los casos 3 y 4 del lote de los cobayos y las cuatro ratas blancas que componen el lote $\mathrm{N}$ ? 3, lograron sobrevivir el período agudo, entrando en una fase subaguda o crónica. Los casos 1 y 2 del lote de las ratas se sacrificaron 22. días después de la inoculación, y los restantes, cobayos y ratas, a los 56 días. En la rata 4 se encontró un quiste hepático subcapsular perteneciente a Cysticercus fasciolaris; otro hallazgo importante en esté mismo animal fue la presencia de pequeños abscesos pulmonares con exudado cremoso.

El comentario de los hallazgos histológicos lo haremos por órganos, dividiendo los animales en dos grandes grupos: casos agudos y casos subagudos o crónicos.

\section{RIÑóN}

En los casos agudos, el riñón presentó lesiones muy semejantes en todos los animales; el cuadro histopatológico renal es el producido por acción tóxica; no podemos decir sin embargo si la lesión primaria es glomerular o tubular, ya que ambos presentan considerables alteraciones. Llama especialmente la atención la congestión intensa de la arteriola aferente y el fcnómeno isquémico del glomérulo; se observa además infiltración reactiva alrededor de la congestión preglomerular, lo que podría explicarse por la filtración de materiales tóxicos en la vecindad. Otro cuadro importante es la lesión metamorfósica presentada por las células de los túbulos; en algunos casos la lesión se extiende hasta los núcleos que aparecen picnóticos o en vías de desintegración. El intersticio presenta reacción linfocitaria difusa, en ocasiones bastante intensa. En los túbulos rectos de la nefrona distal se encuentran con frecuencia cilindros hialinos. Los parásitos se presentaron en todos los casos excepto en el cobayo 2; el hallazgo de pseudoquistes a diferentes alturas de los túbulos renales es de suma importancia, ya que esto significa que posteriormente van a ser eliminados en la orina, siendo ésta por lo tanto un material infestante. En el ratón 2 la localización de los parásitos fue más alta ya que se los encontró en el glomérulo. De gran interés nos ha parecido la presencia de una membrana pseudoquística demostrada mediante la coloración con carbonato de plata. La presencia de esta membrana pseudequística argentófila había sido ya señalada por RODHAIN y GERBZOFF (7) y por FrenkEL. (4); los primeros lograron colorearla por el método de Río Hortega-Kanzler y Frenkel con carbonato de plata, según la técnica de Wilders; nosotros hemos utilizado la técnica de Laidlaw para coloración de retículo (6). En el ratón 1 no se encontraron toxoplasmas en el túbulo ni en el glomérulo, pero se los encontró en el espesor de la cápsula renal. De los dos cobayos que hemos incluído en este grupo, sólo en el primero se observaron parásitos localizados en la cápsula. 
En el grupo considerado como casos subagudos o crónicos, los hallazgos anatomapatológicos son el resultado de la evolución de un período agudo, de tal manera que los animales que sobrevivieron la crisis inicial desarrollaron procesos en los cuales la reacción es más proliferativa que exudativa. Los fenômenos metamorfósicos se presentan en todos los casos afectando las células de los túbulos. En algunos animales se observa hipotrofia de la nefrona distal. Los fenómenos congestivos son bastante frecuentes, no observándose, en general, una localización preglomelular; en muy pocas ocasiones se observó hialinosis arteriolar.

$\mathrm{BAZO}$

En los casos agudos se presentó aumento grande del componente retículoendotelial, con disminución de la pulpa blanca y desaparición de la estructura típica de los folículos de Malpighi. La pulpa roja aparece muy congestionada, observándose en ocasiones gran cantidad de células cargadas de hemosiderina granular. Los parásitos se encontraron en todos los animales que componen este grupo; se los observa la mayoría de las veces en forma endocelular y en relación o no con violentas zonas de necrosis de aspecto acidófilo y gran cantidad de detritos celulares.

En el segundo grupo (subagudos o crónicos) la proliferación retículoendotelial fue igualmente evidente pero las zonas de necrósis están en franco período de cicatrización. En ninguno de estos casos se encontraron parásitos.

\section{HÍGADO}

Los fenómenos metamorfósicos fueron constantes y de bastante intensidad en los casos agudos; la mayoría de las células hepáticas tienen el citoplasma vacuolizado y en algunas ocasiones los núcleos presentan fenómenos desintegrativos. En los espacios portales se observa intensa congestión y reacción inflamatoria en la vecindad, hecho que podría atribuirse a la filtración de material tóxico. En todos los animales de este grupo se encontraron los parásitos, localizados con mucho mayor frecuencia hacia la periferia del órgano; muchas veces se los encuentra en la vecindad de zonas de necrosis, alrededor de las cuales hay generalmente infiltración de tipo linfoplasmocelular; en ocasiones se observan formaciones microgranulomatosas. Nos llamó especialmente la atención la presencia de enormes cantidades de parásitos en el espesor de la cápsula de Glisson y en los espacios subcapsulares; los toxoplasmas encontrados en estas regiones son la mayoría de las veces libres. El hecho de haber encontrado estas grandes infiltraciones parasitarias en estas zonas, nos ha sugerido la idea de que la forma de invasión en este caso sea a través de la cápsula, ya que ésta, está bañada por el el exudado peritoneal, muy rico en parásitos, producido por la infección toxoplásmica; por otra parte está la mayor frecuencia con que se encuentran zonas de necrosis y toxoplasmas hacia la periferia del órgano como mencionábamos al principio. En los cobayos, la cápsula hepática se encuentra notablemente aumentada de espesor debido a la perihepatitis producida por la organización de la 
fibrina en su superficie; en el ratón 3 el exudado fibrinoso depositado entre los lóbulos hepáticos llegó a soldarlos completamente, y en las redes de fibrina se encontraron grandes cantidades de parásitos.

En los casos subagudos o crónicos no se pudieron evidenciar los parásitos ni en la cápsula ni en el interior del órgano. Los fenómenos metamorfósicos fueron constantes, así como la presencia de una infiltración difusa, y en algunos casos microgranulomatosa. Los cuadros congestivos se presentaron con bastante intensidad. En la rata 4 se encontró un quiste subcapsular perteneciente a Cysticercus fasciolaris.

\section{MIOCARDIO}

En ningún caso se encontraron parásitos en este órgano. La lesión miocárdica principal es de tipo patósico; algunas fibras presentan fenómenos de tipo coagulativo con homogeneización eosinofílica, cuadro que se observó con mayor intensidad en los casos agudos. En algunas ocasiones se encuentra un infiltrado linfocitario intersticial que no llega a adquirir la forma de una miocarditis de importancia. Las fibras presentan una ligera disminución de la estriación transversal y longitudinal, principalmente en los casos crónicos.

\section{Pulmón}

Los fenómenos congestivos interalveolares se observaron en todos los animales. En algunos casos, sobre todo en los cobayos hay lesiones de tipo bronconeumónico de mediana intensidad, en un caso en relación con parásitos. En la rata 4 se observa un exudado purulento alrededor del cual, en algunas ocasiones se encuentra tejido de granulación. Muchas veces se presenta fluidificación de la parte central de pequeños granulomas formados por histiocitos, plasmacélulas y reticulocitos; sin embargo, creemos que estas formaciones no tienen ninguna relación con la toxoplasmosis, por el tipo de la lesión, por lo que lo hemos considerado como un proceso inespecífico.

\section{Sistema NERVIOSO CENTRAL}

En el tejido nervioso no nos fue posible evidenciar lesiones exudativas ni proliferativas. Los parásitos formando pseudoquistes típicos, como se les encuentra con frecuencia en estos territorios, tampoco fueron observados.

Resumiendo, podemos decir que del estudio histopatológico que hemos realizado, se desprende que aquellos animales que sucumben durante el período agudo de la enfermedad, presentan lesiones que son evidentemente tóxicas; los cambios más graves se presentan a nivel de los parénquimas (renal, hepático miocárdico, etc.), en forma de metamorfosis, con evidenciación de complejos lipoproteicos, resultado de la acción de una fuerte toxina sobre el protoplasma; en las estructuras mesenquimovasculares (glomérulo renal, espacio de Disse, pulpa esplénica, árbol arterioso en general), se presentan fenómenos congestivos de tipo 
vaso-paralítico, exudación y proliferación de las células propias del tejido conjuntivo. Es indiscutible que estos cuadros son el resultado de la acción de una toxina de acción lenta; los resultados obtenidos por VARela, Roch y Vézquez (10) eliminan la posibilidad de que el toxoplasma produzca una toxina (toxotoxina) de acción letal inmediata al inyectarla por vía endovenosa. La acción de esa toxina produciría la muerte entre el 50 y el $6^{\circ}$ día después de la inoculación en los ratones y algunas veces en los cobayos, como ha sucedido en nuestro lote. Las ratas parecen ser bastante más resistentes a la acción tóxica.

Si los animales robreviven el período agudo, las lesiones al principio son siempre orientadas hacia una parenquimatosis polivisceral, pero al mismo tiempo, a nivel de los tejidos mesenquimovasculares la respuesta proliferativa retículoendotelial predomina absolutamente sobre los fenómenos exudativos. Las zonas de necrosis van evolucionando hacia la fibrosis; este estado lo hemos denominado subagudo o crónico.

Queremos subrayar el hecho de que en ninguno de los casos comprendidos en este último grupo pudimos encontrar parásitos; es prcbable que la respuesta inmunitaria sea lo suficientemente fuerte como para eliminar la mayoría de los toxoplasmas. Probablemente los organismos que sobreviven, con el tiempo van a provocar lesiones granulomatosas en el sistema nervioso y cardiovascular principalmente, lo que al cabo de algunos meses determina la muerte del animal.

\section{RESUMEN}

Los autores hacen un estudio de las lesiones producidas en los animales de laboratorio por la cepa costarricense de Toxoplasma gondii llamada "La Esperanza", nombre del caserío de donde procede, y que se mantiene por medio de pasajes en ratones. El trabajo se hizo selecionando lotes de cuatro animales de ratones blancos, ratas blancas y cobayos, criados en el laboratorio durante varias generaciones, para garantizar su salud; estos lotes fueron inoculados con dosis de $100.000,200.000$ y 300.000 parásitos por animal, respectivamente. De estos animales, unos murieron a causa de la enfermedad y otros se sacrificaron en la cámara de gases, pero en todos los casos se practicó la autopsia y los órganos así recogidos (riñón, bazo, hígado, pulmón, miocardio y encéfalo), fuercn fijados en formol al $10 \%$ y luego incluídos en parafina. Los cortes obtenidos fueron teñidos, tanto con los métodos de rutina, como mediante técnicas especiales.

En el análisis de' los resultados se destacan algunos hechos de interés: los ratones blancos son muy susceptibles a la toxoplasmosis; mueren regularmente en seis días, cosa que ya habíamos observado en el mantenimiento de la cepa. En el lote de los cobayos, dos murieron espontáneamente al mismo tiempo que los ratones y dos fueron sacrificados posteriormente. Las ratas, se mostraron bastante resistentes, por lo que fue necesario sacrificarlas al cabo de un tiempo conveniente.

El examen histológico también permitió hacer algunas observaciones de importancia: de acuerdo con las lesiones encontradas se ha dividido a los anio 
males en dos grupos: los casos agudos que son los que presentaron fenćmenos patósicos a nivel de los parénquimas y reacción predominantemente exudativa en las estructuras mesénquimovasculares; en los casos clasificados como sub-agudos o crónicos persisten las parenquimatosis, pero la reacción proliferativa retículoendotelial predomina sobre la exudativa. El hallazgo de pseudoquistes en el lumen de los túbulos renales se ha considerado de mucha importancia, ya que esto condicionaría la infectividad de la orina. Otro hecho importante fue la presencia de una membrana pseudoquística argentófila, lo que comprueba la opinión de otros autores.

\section{SUMMARY}

A study is presented of lesions caused on laboratory animals by the Costa Rican strain of Toxoplasma gondii known as "La Esperanza" after the area where it was found, and which is kept alive in mice. Lots of four white mice, white rats, and guinea pigs were used, from stocks raised in the laboratory for several generations to insure their health.

Each mouse was given an inoculation of 100,000 parasites; each rat, 200,000 , and each guinea pig 300,000. Some of the inoculated animals died from the infection, the rest were killed in a gas chamber. In all cases autopsies were made and organs (kidney, spleen, liver, lung, heart and brain) were fixed in $10 \%$ formalin and embedded in paraffin.

Sections were stained with the usual hematoxylin-cosin combination, with Laidlaw's silver carbonate, and Gallego's triple stain.

White mice were found to be highly susceptible to toxoplasmosis. Individuals died regulary in six days, a fact already noted in keeping the strain alive. Two of the guinea pigs died at the same time and two were killed later. Rats showed more resistance, and all were killed after some time.

Histological examination showed animals to $b$ divided in two groups according to the lesions found. Acute cases showed parenchymatic pathotic phenomena, and predominantly exudative reaction in mesenchymo-vascular structures. In subacute or chronic cases parenchymatoses were also present, but reticuloendothelial proliferative reaction prevailed over the exudative.

Pseudocysts were found in the lumen of renal tubules, a fact considered of much importance, as it would establish the infectivity of urine. Another important finding was the presence of an argyrophilic pseudocyst membrane, confirming other author's opinions.

\section{RIASSUNTO}

Gli AA. presentano uno studio delle lesioni provocate in animali di laboratorio, da un ceppo costarricense di Toxoplasma gondii, chiamato "La Esperanza", in ricordo del luogo di provenienza del paziente; tale ceppo si mantenne vitale per mezzo di passaggi in topolini. 
Si selezionarono tre lotti di quattro topolini bianchi, quattro ratte bianche, e quattro cavie che per varie generazioni erano cresciuti in laboratorio per essere certi che erano immuni da altre infestazioni. Questi animali furono inoculati con dosi di 100.000, 200.000 e 300.000 parassiti rispettivamente in topolini, in ratte ed in cavie. Di questi alcuni morirono a causa della parassitosi stessa, altri furono sacrificati in camera a gas, tutti furono autopsiati ed i seguenti organi: rene, milza, fegato, polmone, miocardio e cervello furono fissati in formalina al $10 \%$ e poi inclusi in paraffina.

Si usarono le seguenti colorazioni: ematossilina-eosina, tricromica di Gallego e impregnazione argentica di Laidlaw.

Analizzado i risultati, si osservŏ che i topolini bianchi erano molto recettivi alla toxoplasmosi e morivano regolarmente dopo sei giorni (cosî come si axeva potuto constatare durante il tempo che si fecero i passaggi per il mantenimento del ceppo). Due cavie morirono contemporaneamente ai topolini, le altre due si sacrificarono con le ratte; queste ultime si mostrarono le piú resistenti ai parassiti.

Le lesioni osservate all'esame istologico furono: di tipo acuto, con processi patosici dei parenchimi e reazioni essudative al livello delle strutture mesenchimo-vascolari; di tipo sub-cronico e cronico con lesioni parenchimatose ed una reazione proliferativa del reticoloendotelio marcata.

Si consideró molto importante il referto di "pseudocisti" nel lume dei tubuli renali dato che questi possono infettare l'urina, e la presenza di una membrana argirofila che le circonda, dato che conferma l'ipotesi di alcuni autori.

\section{BIBLIOGRAFIA}

1. Céspedes, R. \& P. Morera

1955. Toxoplasmosis. Estudio clínico patológico de los primeros casos reportados en Costa Rica. Rev. Biol. Trop. 3 (1):1-30.

2. Céspedes, R. \& P. Morera

1955. Toxoplasmosis humana generalizada. Rev. Biol. Trop. 3 (2):183-202.

3. Christen, R. \& ERica Thiermann

1953. Influencia de la constitución genética en la susceptibilidad del ratón blanco frente a la infección por, Toxoplasma gondii. Bol. Inf. Parasit. Chilenas, 8 (4): $79-81$.

4. FRENKEL, J. K.

1956. Pathogenesis of toxoplasmosis and infestions with organism resembling Toxoplasma. Ann. New York Acad. Sc., 64 (2):215-251.

5. LANGERON, M.

1949. Précis de Microscopie. XIII + 1430 pp. Masson \& Cie. París.

6. LiLlie, R. D.

1954. Histopatbologic technic and practical bistochemestry. IX +501 pp. The Blackiston Co., Inc., New York. 
7. Rodhain, J. \& M. A. Gerbtzoff

1951. Au sujet de la membrane limitant des pseudokystes de toxoplasms. Compit. Rend. Soc. Biol., 145 (9-10):766-768.

8. RomeIs, B.

1928. Guia-formulario de técnica bistológica. XV + 722 pp. Editorial Labor S. A.., Barcelona.

9. Thiermann, ERica \& R. Christen

1953. Influencia de la edad, del sexo y de las vías de inoculación en el curso de la toxoplasmosis experimental del ratón. Bol. Inf. Parasit. Chilenas, 8 (3): 45-49.

10. Varela, G., E. Roch \& A. Vázquez

1955. Virulencia, cultivo, polisacáridos, toxinas y la prueba del colorante, estudiados con una cepa de Toxoplasma gondii. Rev. Inst. Salub. Enf. Trop., 15 (2) : 73-80. 
Fig. 1: Exudado peritoneal de ratón: típicas formas de Toxoplasma gondii; obsérvense formas tanto extra como endocelulares (Col. Giemsa; $1000 \times$ ).

Fig. 2: Riñón: dilatación y congestión de la arteriola aferente e infiltración linfocitaria en la vecindad (Col. hematoxilina-eosina; $300 \times$ ).

Fig. 3: Riñón: formas típicas del parásito en el espesor de la cápsula renal (Col. hematoxilina-eosina; $100 \times$ ).

Fig. 4: Riñón: congestión e intensa infiltración preglomerular (Col. hematoxilina-eosina; $100 \times$ ). 


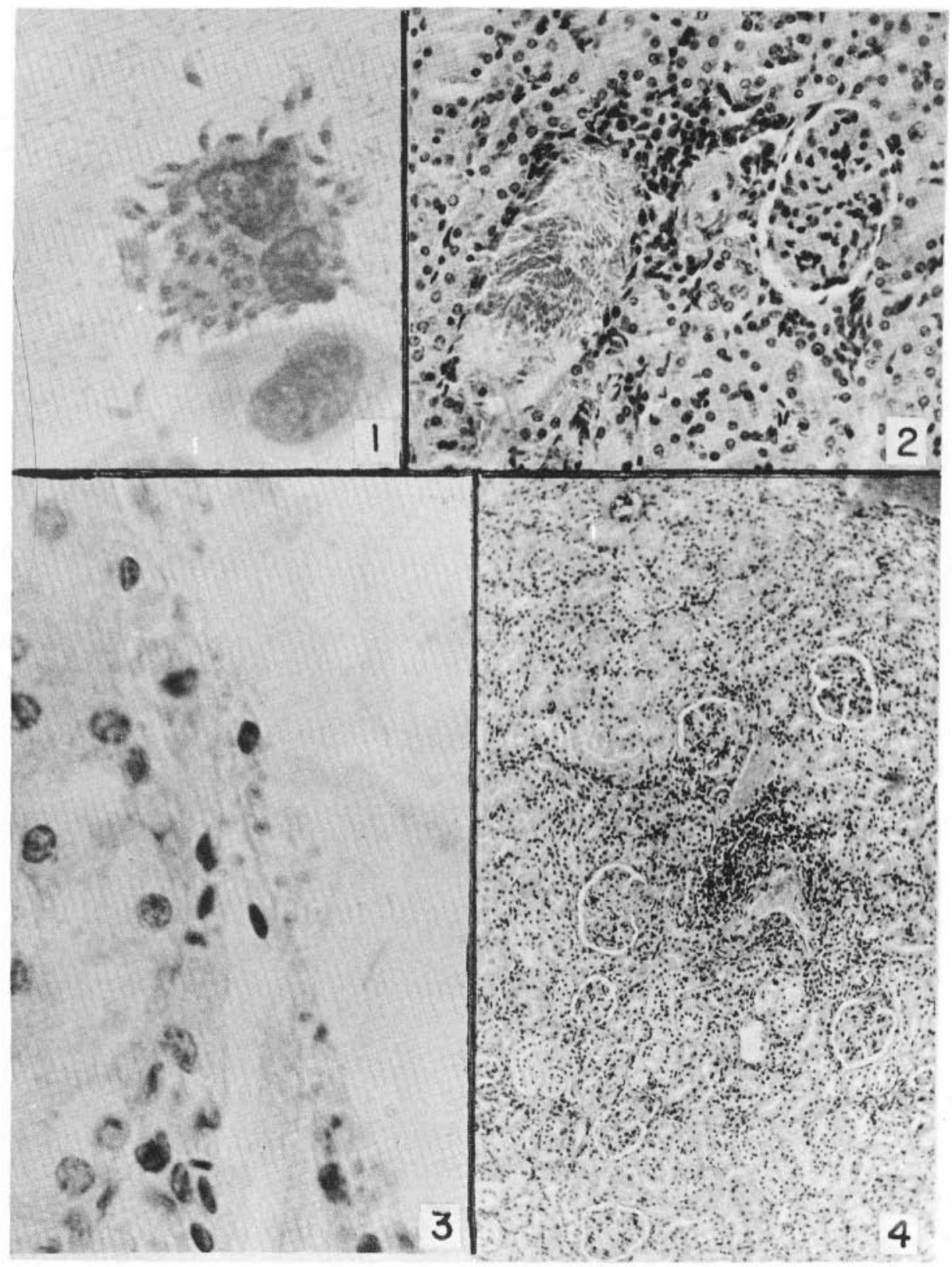


Fig. 5: Riñón: pseudoquiste en el lumen de un túbulo contorneado de primer orden (Col. hematoxilina-eosina; $450 \times)$.

Fig. 6: Riñón: pseudoquiste en el interior de un glomérulo de Malpighi (Col. hematoxilina-eosina; $300 \times$ ).

Fig. 7: Riñón: detalle de la figura anterior para observar los parásitos con mayor ritidez (Col. hematoxilina-eosina; $1000 \times)$.

Fig. 8: Riñón: grupos de pseudoquistes en el interior de los túbulos contorneados '(Col. tricrómico de Gallego; $450 \times)$. 


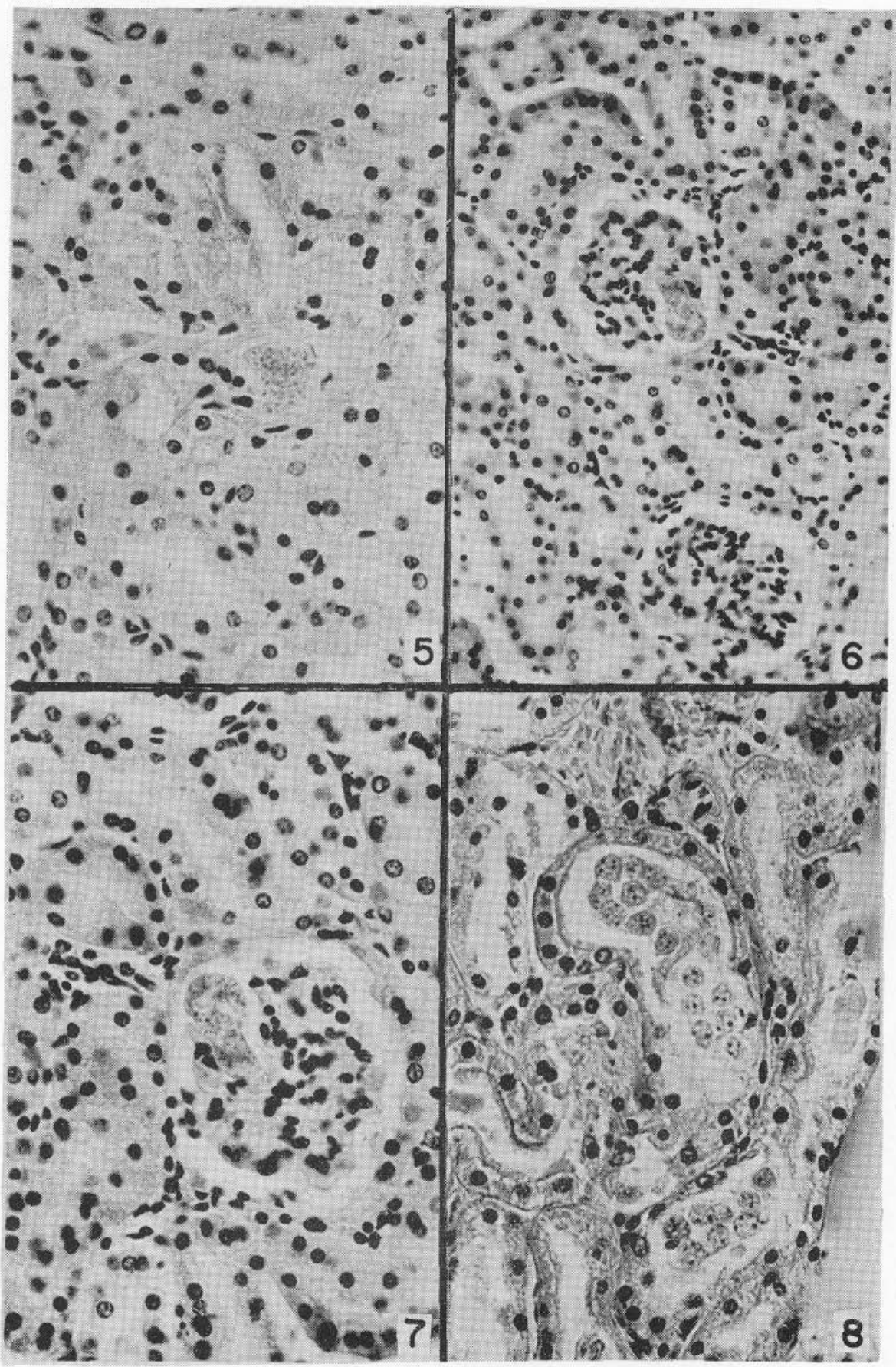


Fig. 9: Riñón: aspecto de los pseudoquistes, coloreados con carbonato de plata, en el interior de los túbulos contorneados (Col. Laidlaw; $450 \times$ ).

Fig. 10: Riñón: congestión intensa de la arteriola aferente al glomérulo; en la vecindad se encuentran gran cantidad de elementos inflamatorios (Col. tricrómico de Gallego; $100 \times)$.

Fig. 11: Riñón: grupo de pseudoquistes en el interior de un túbulo contorneado de primer orden; en la vecindad se observa infiltración intersticial de linfocitos (Col, hematoxilina-eosina: 45()$\times)$ ).

Fig. 12: Riñón: vista panorámica en la que pueden observarse varios grupos de pseudoquistes en el interior de los túbulos renales (Col. Laidlaw; $100 \times$ ). 


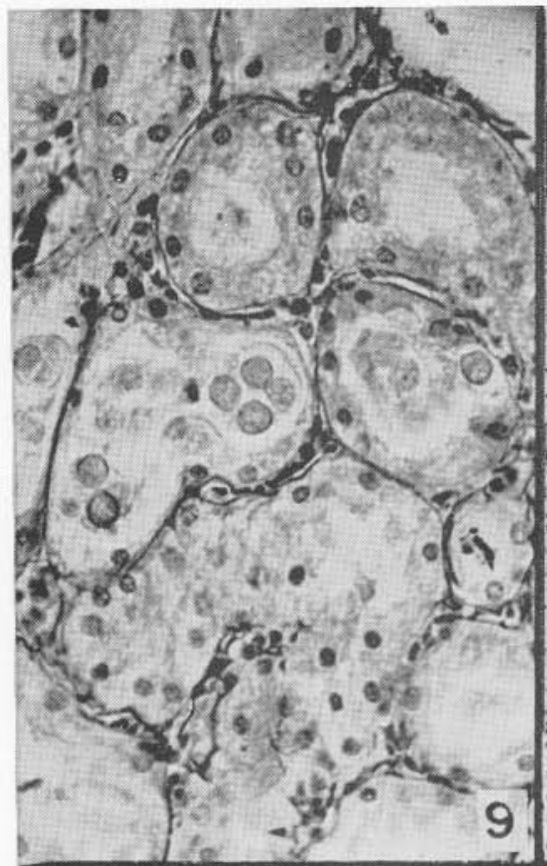

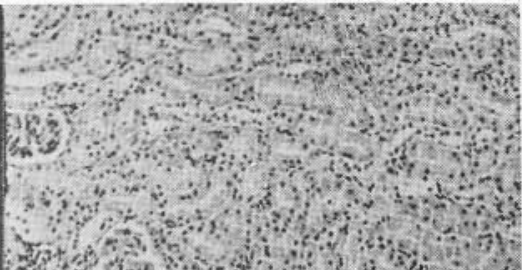

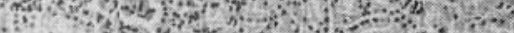

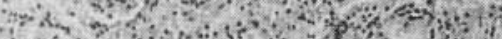

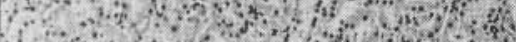

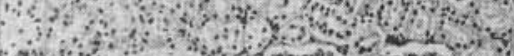

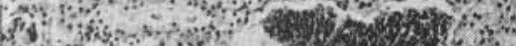

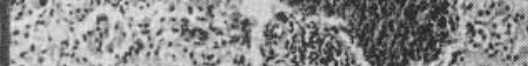
i. ${ }^{2}$.

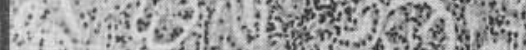

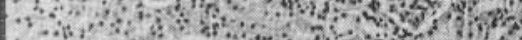

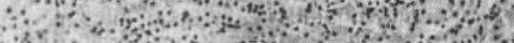

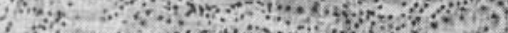

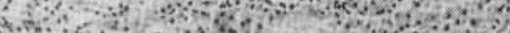

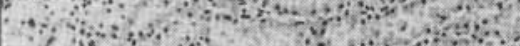

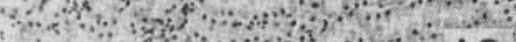

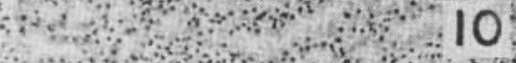

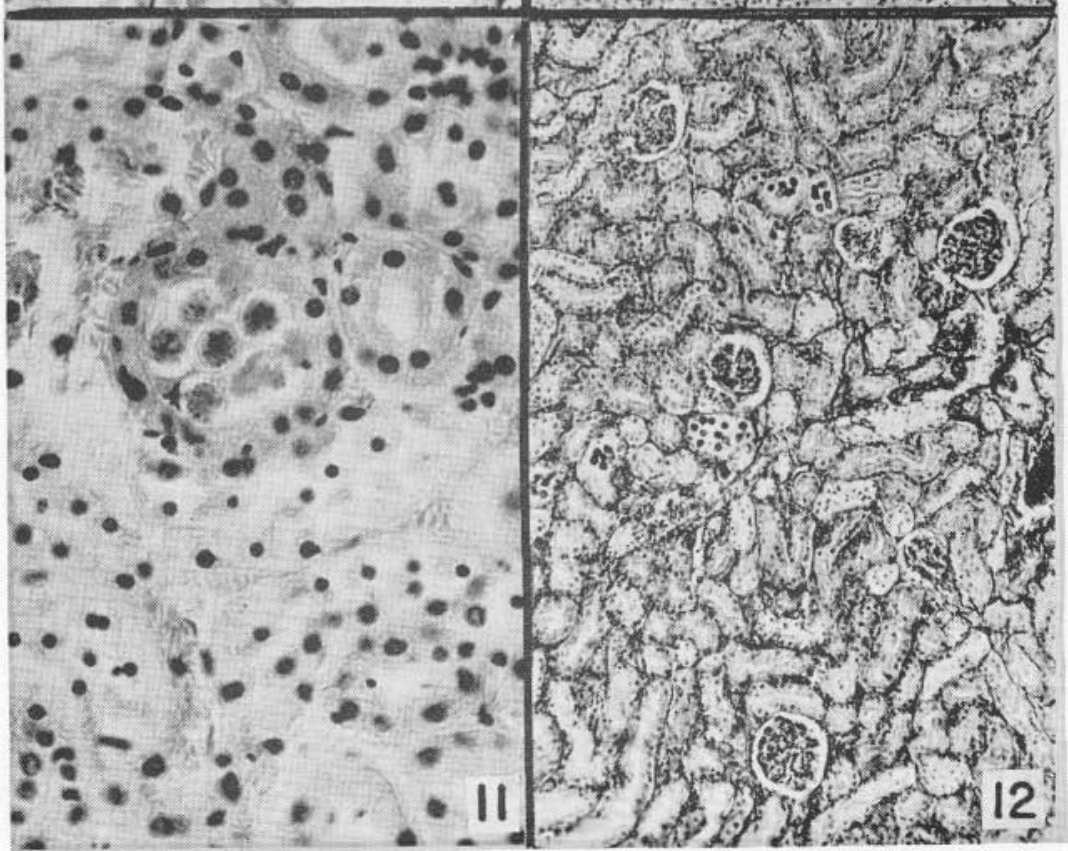


Fig. 13: Riñón: detalle de dos de los grupos de la figura an: terior; obsérvese la presencia de una membrana argen- tófila pseudoquística (Col. Laidlaw; $450 \times$ ).

Fig. 14: Bazo: zona de necrosis de aspecto eosinófilo en la pulpa roja; puede observarse hiperplasia tanto de la pulpa blanca como de la roja (Col. tricrómico de Gallego; $450 \times)$.

Fig. 15: Bazo: grupos de macrófagos conteniendo típicas formas de toxoplasma (Col. tricrómico de Gallego; $1000 \times$ ).

Fig. 16: Bazo: macrófago situado en la parte central de un granuloma esplénico (Col. tricrómico de Gallego; $1000 \times)$. 

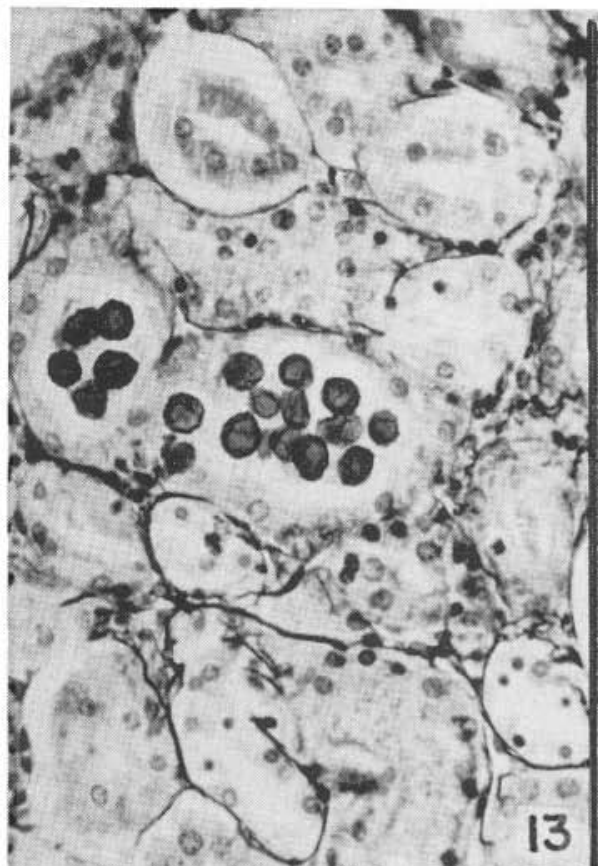

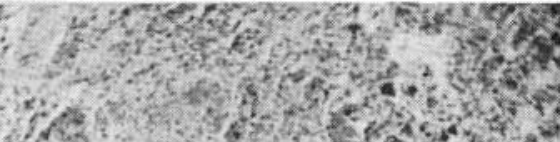

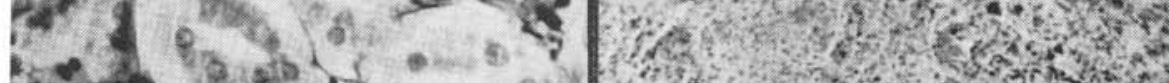

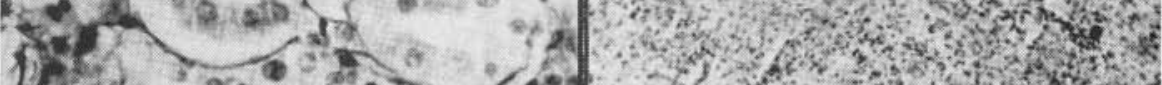

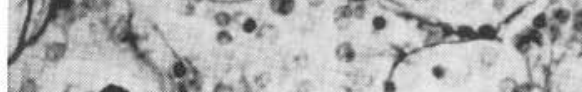
Fis is 2.1.

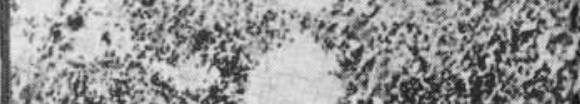
8.

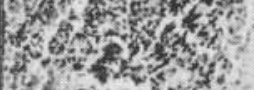
f. Fif -34.

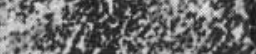
(2)

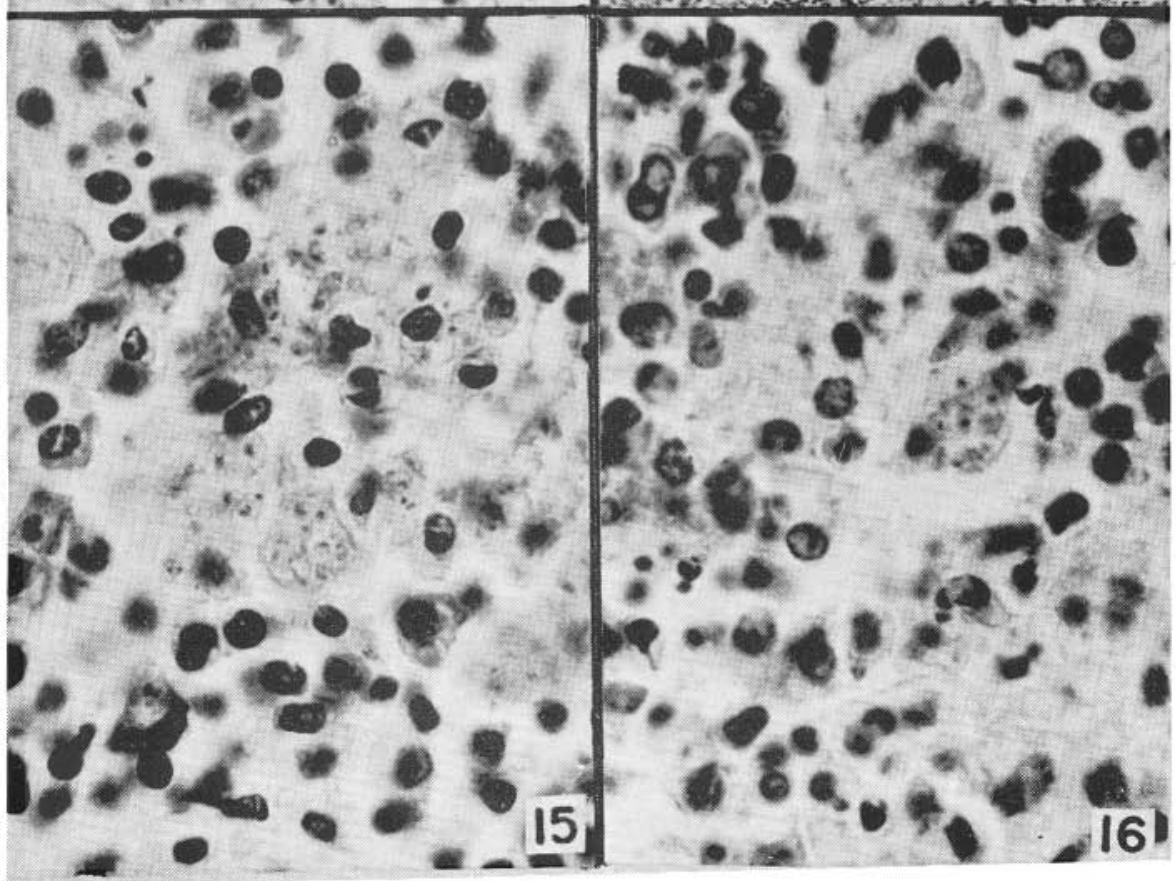


Fig. 17: Bazo: hiperplasia reticular que rodea a una zona de necrosis de aspecto acidófilo (Col. hematoxilina-eosina; $300 \times)$.

Fig. 18: Bazo: detalle de un macrófago repleto de toxoplasmas de forma típica (Col. hematoxilina-eosina; $1000 \times$ ).

Fig. 19: Hígado: las células hepáticas presentan metamorfosis albuminoideo adiposa de bastante intens:dad (Col. hematoxilina-eosina; $1000 \times$ ).

Fig. 20: Hígado. infiltración linfocitaria difusa, entre la cual pueden observarse gran cantidad de parásitos (Col. hematoxilina-eosina: $450 \times$ ). 


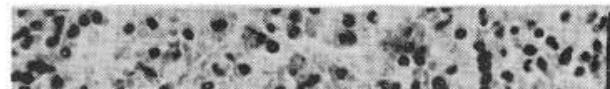

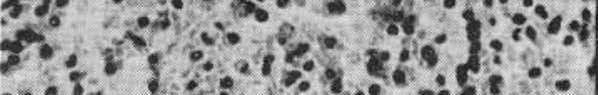

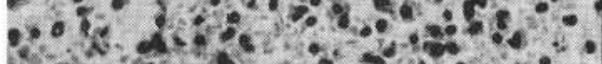

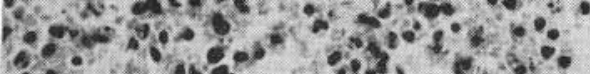

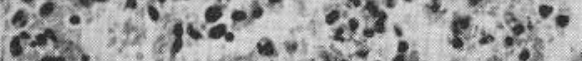

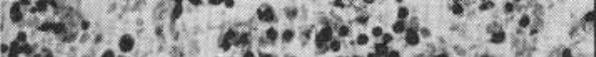
3.

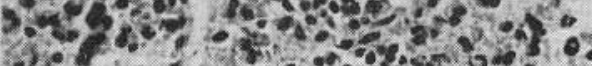

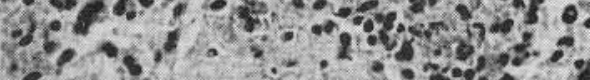

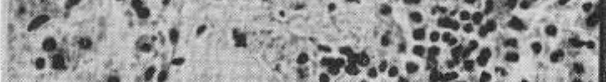

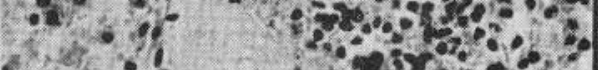

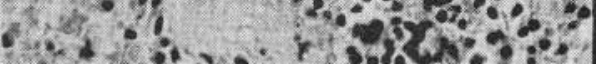

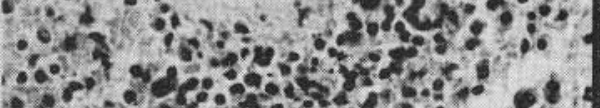

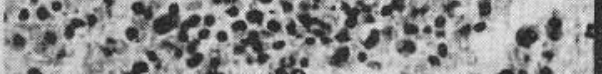

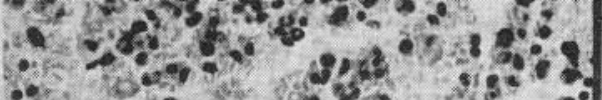
2. $6.0-24.45$ ....

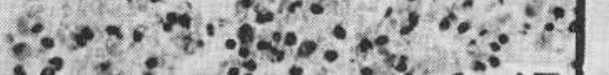
30.000 .017
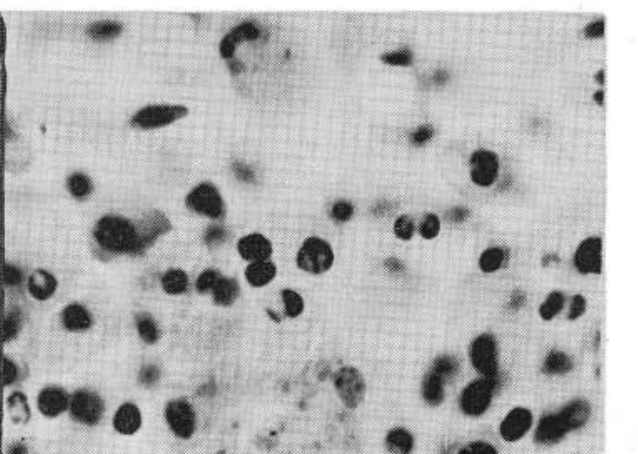

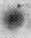
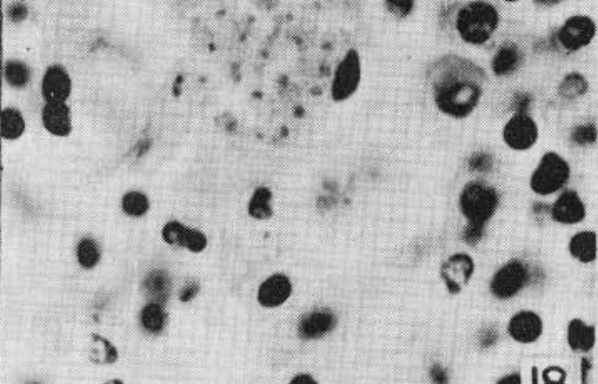

$+2.0 \%$

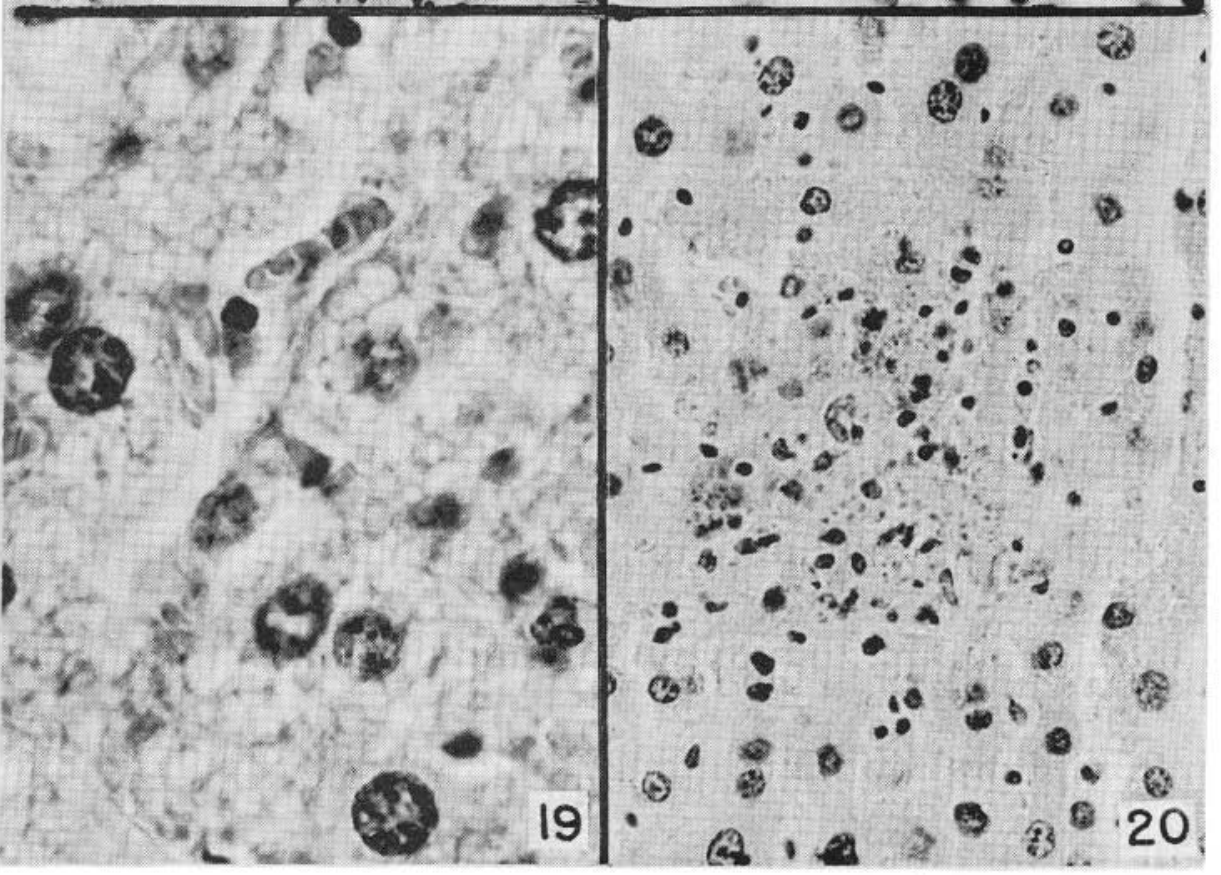


Fig. 21: Hígado: otro aspecto del cuadro anterior; obsérvese además la vacuolización de las células hepáticas (Col. hematoxilina-eosina; $450 \times$ ).

Fig. 22: Hígado: gran cantidad de parásitos en el espesor de la cápsula de Glisson (Col. tricrómico de Gallego; $1000 \times$ ).

Fig. 23: Higado: intensa congestión arteriolar en los espacios de Disse; se nota también infiltración linfocitaria difusa en el interior del lobulillo hepático (Col. tricrómico dc Gallego; 100 X).

Fig. 24: Higado: la cápsula de Glisson y los espacios subcapsulares están infiltrados por gran cantidad de parásitos. Obsérvese también la metamorfosis de las células parenquimatosas (Col. tricrómico de Gallego; $450 \times$ ). 


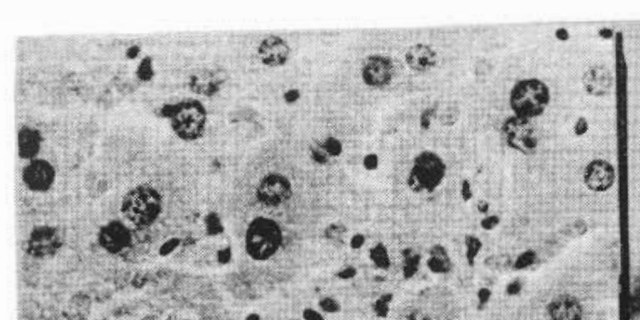

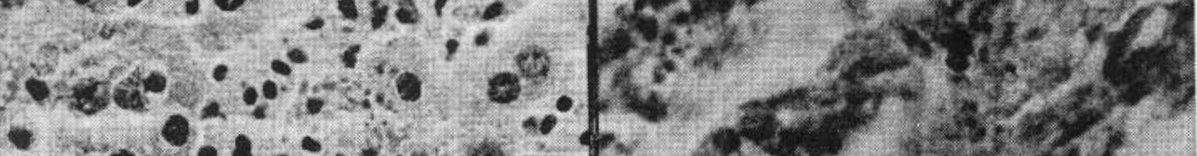

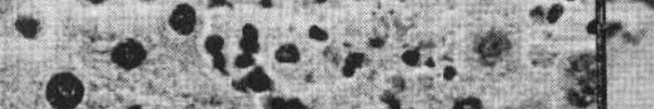
$0.0,0.21$

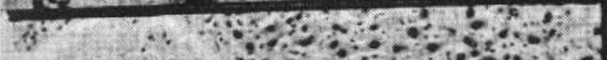

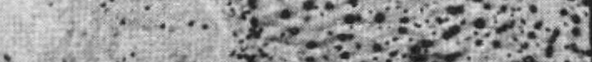

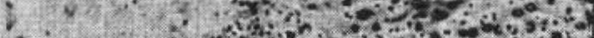

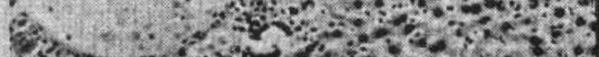

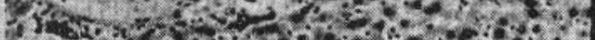

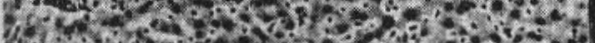

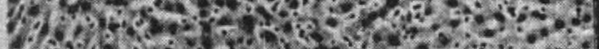

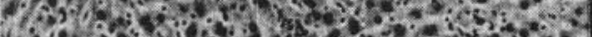

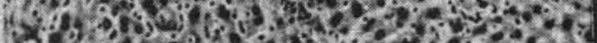

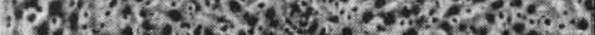

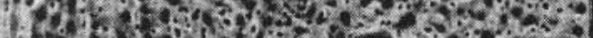

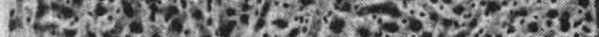

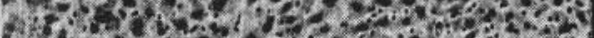

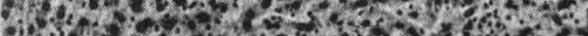

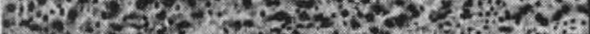

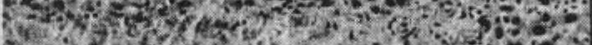

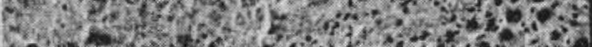

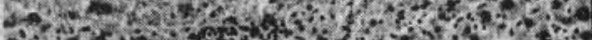

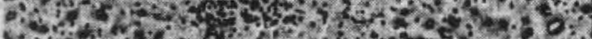

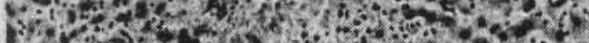

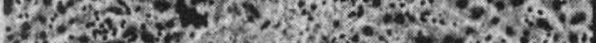
a. ox.

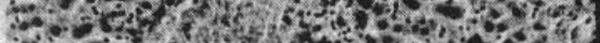

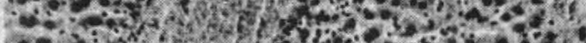

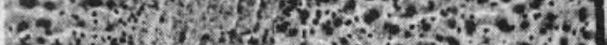

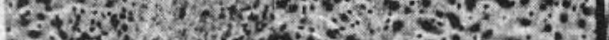

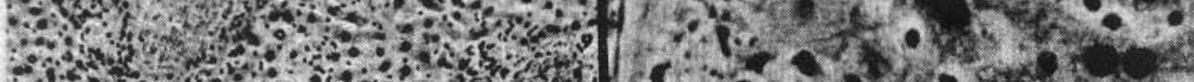
*n

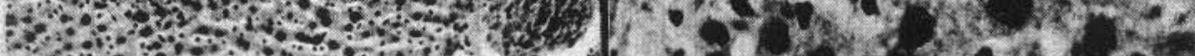

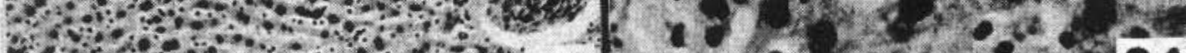
2x.

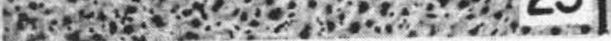

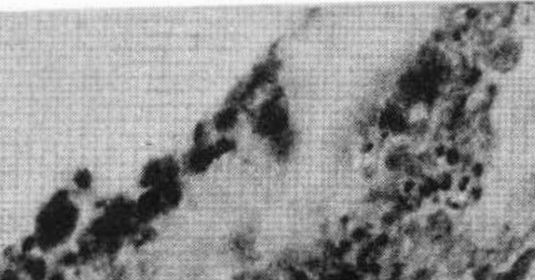

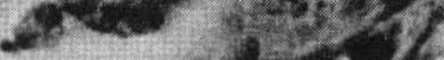
(2) 
Fig. 25: Higado: detalle de la figura anternor ( $\mathrm{Col}$. tricrómico de Gallego; $100(0 \times)$

Fig. 26: Hígado: zona de necrosis de aspecto granular acidófilo en un espacio interlobulillar (Col. hematoxilina-eosina; 10()$\times)$.

Fig. 27: Hígado: exudado fibrinoso que une dos lóbulos hepáticos hasta llegar prácticaniente a soldarlos (Col. hematoxilina-eosina; $3(0) \times)$.

Fig. 28: Hígado: un detalle de +la figura anterior en el que se aprecia la gran cantidad de parásitos existentes entre las redes de fibrina (Col. tricrómico de Gallego, $100(0 \times x)$. 


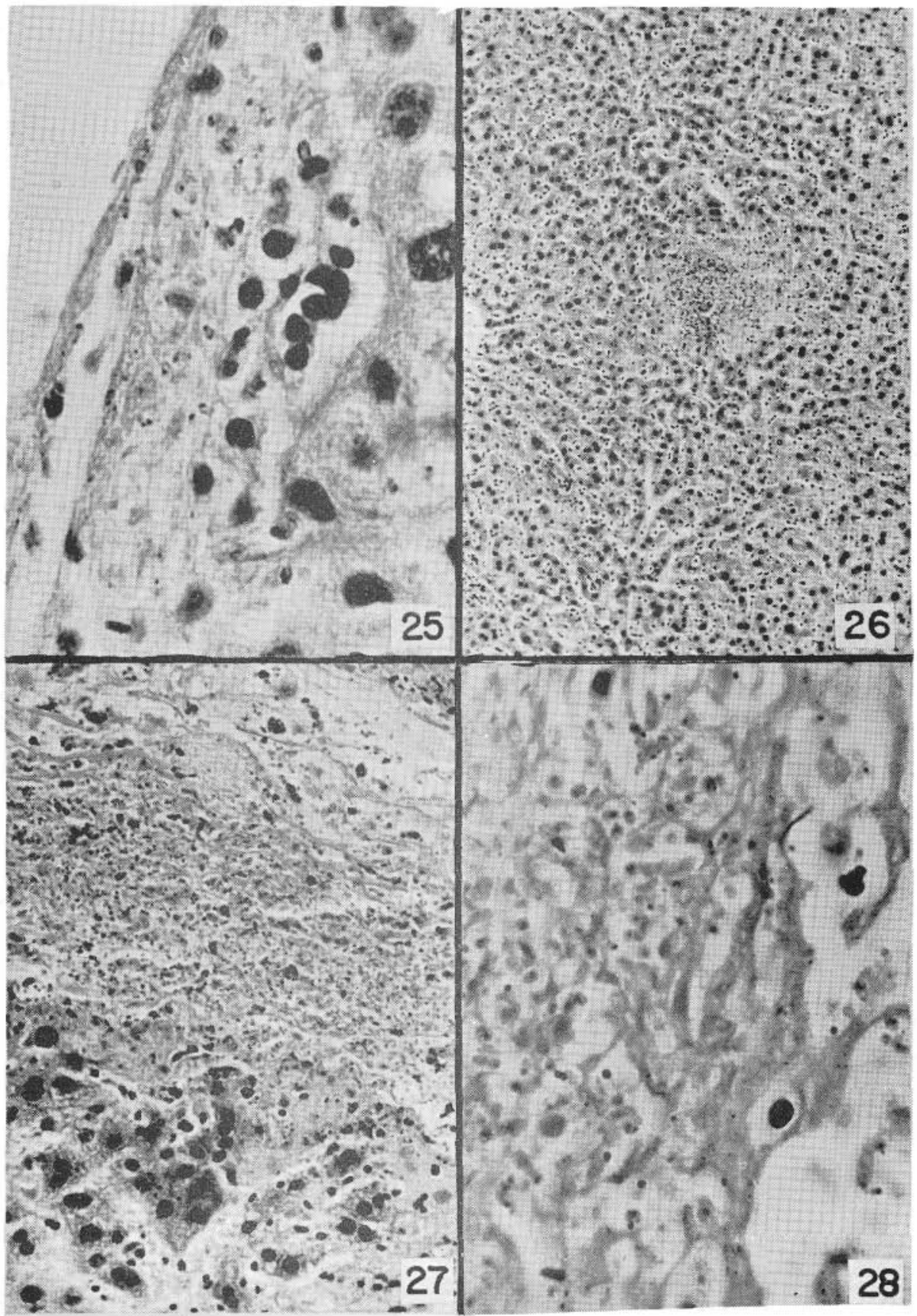


Fig. 29: Hígado: focos necróticos celel parénquima hepático. infiltración linfocitaria y gran cantidad de parásitos (Col. hcmatoxilina-eesina; $450 \times)$.

Fig. 30: Miocardio: en la parte superior aparece una fibra que presenta homogeneización eosinofílica; más abajo se puede ver un pequeño foco de reacción inflamatoria Col. hematoxilina-eosina; $450 \times$ ).

Fig. 31: Pulmón: congestión de los capilares interalveolares (Col. hematoxilina-eosina; $100 \times$ ).

F.g. 32: Pulmón: foco de infiltrado inflamatorio alrededor de un bronquio (Col. hematoxilina-eosina; $300 \times$ ). 

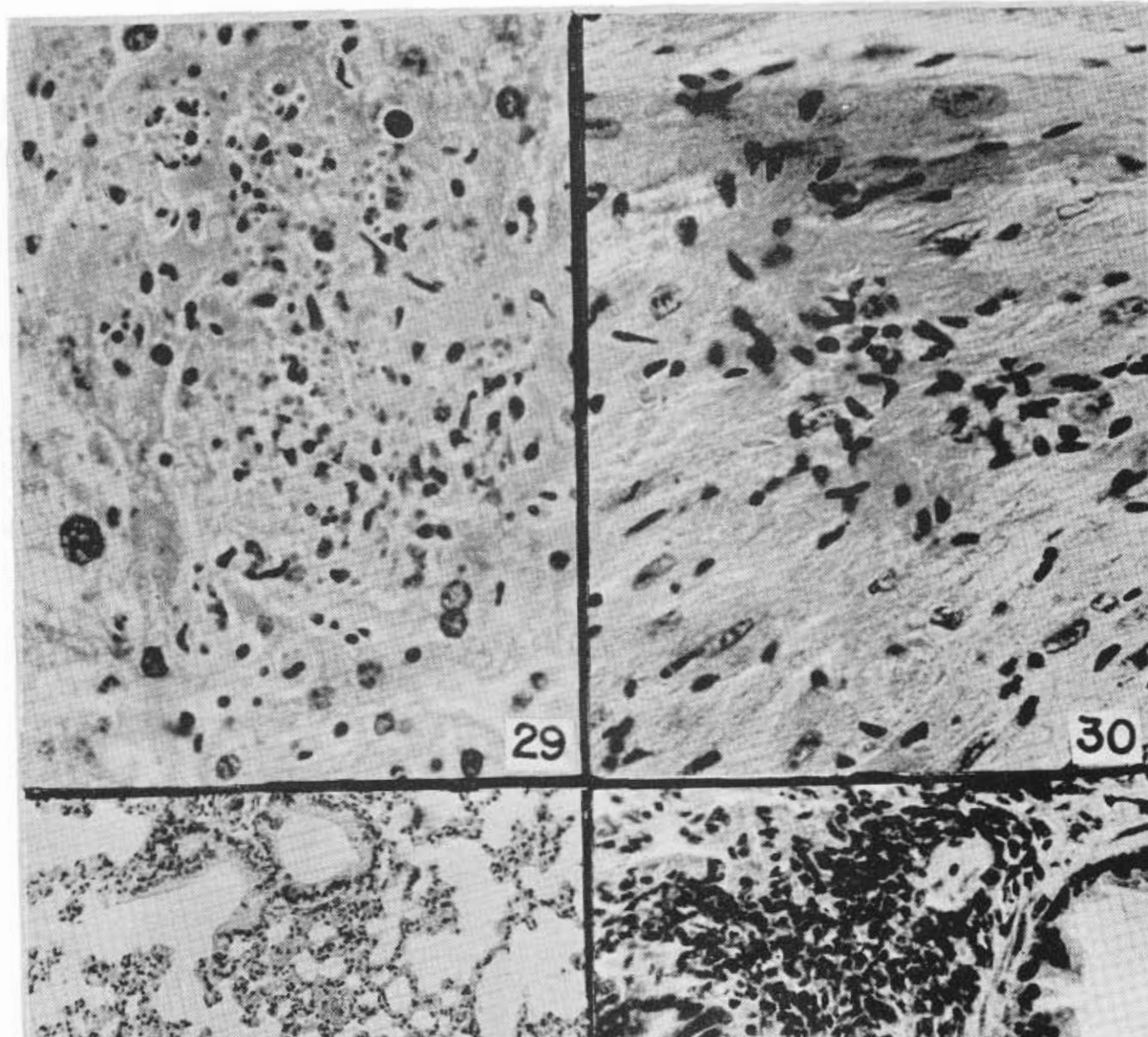
Fig. 33: Riñón: cilindruria masiva de los túbulos de la nefrona distal (Col. hematoxilina-eosina; $100 \times$ ).

Fig. 34: Riñón: grupo parasitario en el espesor de la cápsula renal (flecha), de forma alargada y bastante compacto (Col. hematoxilina-eosina; $450 \times$ ).

Fig. 35: Riñón: intensa congestión de las arteriolas interlobulares, que a veces adquiere la forma de pequeñas hemorragias (Col. hematoxilina-eosina; $100 \times$ ).

Fig. 36: Riñón: en algunos puntos se pueden apreciar pequeños hilos de material proteico (sinequias) que unen el glomérulo con la hoja visceral de la cápsula de Bowman: el glomérulo tiene cierta tendencia a la lobulación (Col. hematoxilina-eosina; $300 \times$ ). 
Ding

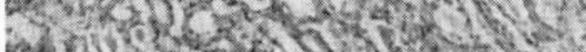
Non $-2 \times 1$

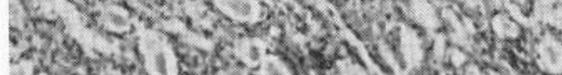

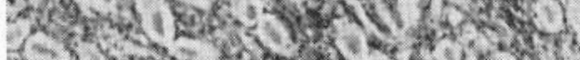

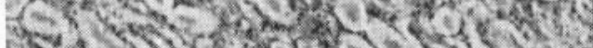
T.

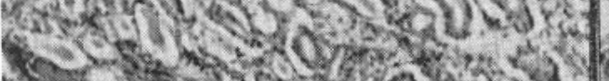

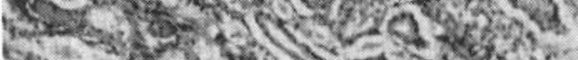
n- 5 - -2

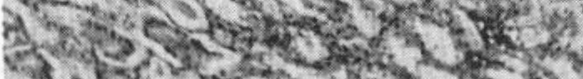

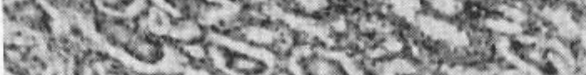

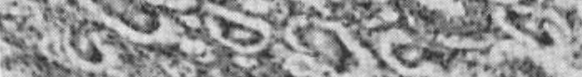
r. - $3,-1,20$ 54 - S S I. 33

बरा

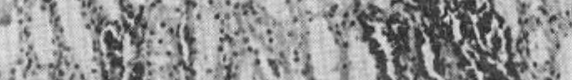
if ${ }^{2}$.

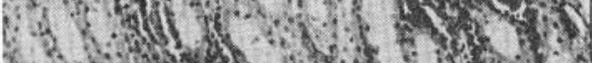

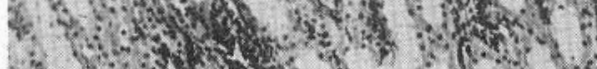

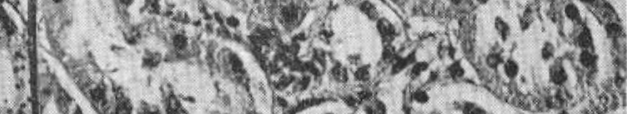

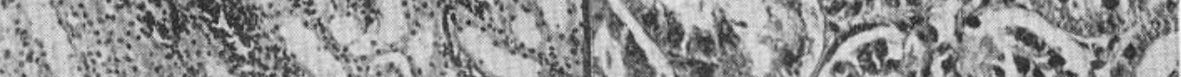

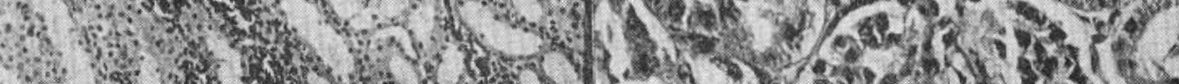
s.

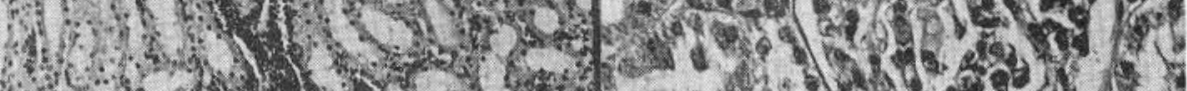

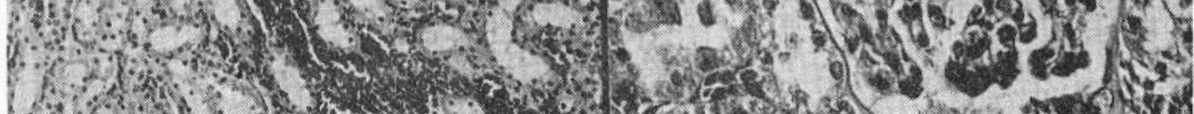

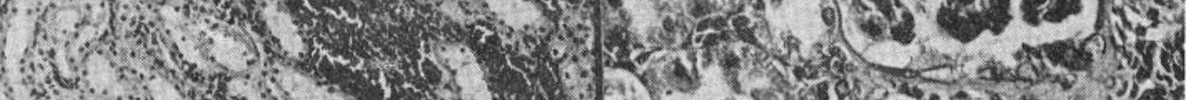

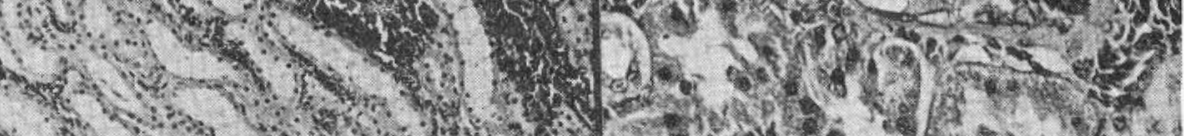
Fis.

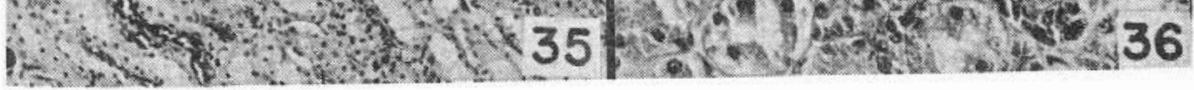


Fig. 37: Bazo: en la pulpa roja, en la vecindad de un folículo de Malphigi se puede ver un pseudoquiste, de forma arredondada y bastante compacto (Col. hematoxilina. eosina: $450 \times)$.

Fig. 38: Bazo: detalle de la figura anterior (Col. hematoxilinaeosina; $1000 \times$ ).

Fig. 39: Bazo: pequeño pseudoquiste situado en la pulpa blanca; obsérvese la intensa reacción reticular en la vecin dad (Col. hematoxilina-eosina; $300 \times$ ).

Fig. 40: Bazo: obsérvese la gran cantidad de macrófagos conte. niendo hemosiderina (Col. hematoxilina-eosina; $100 \times$ ). 

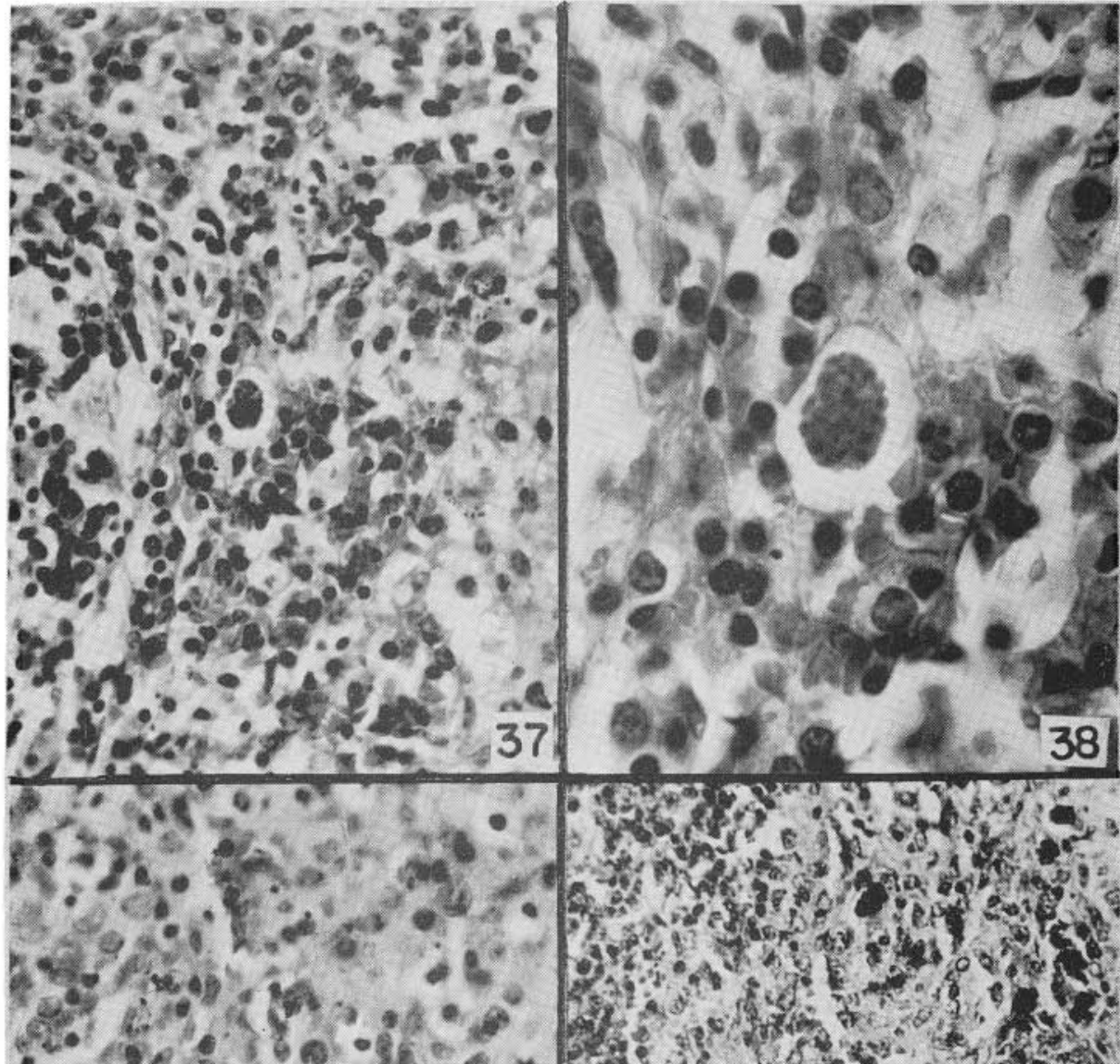

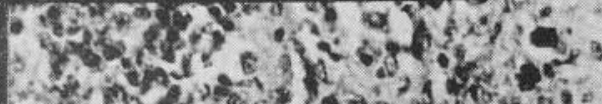

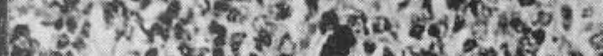

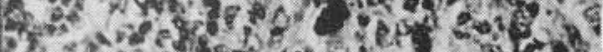
Q7. $32^{2}$ in

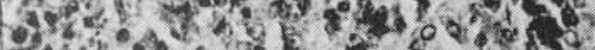

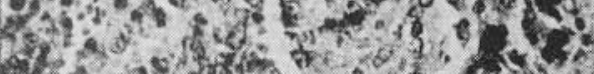
f.

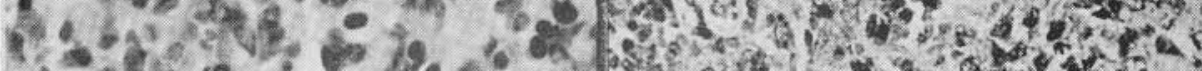

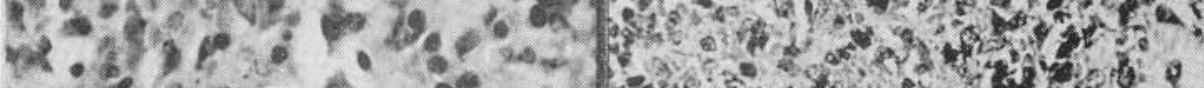

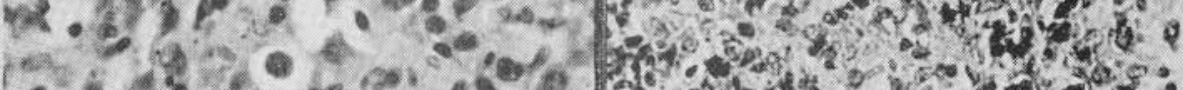

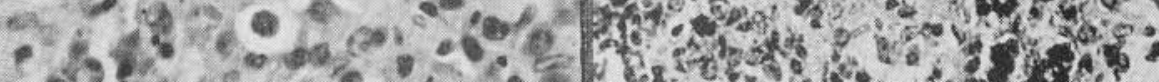

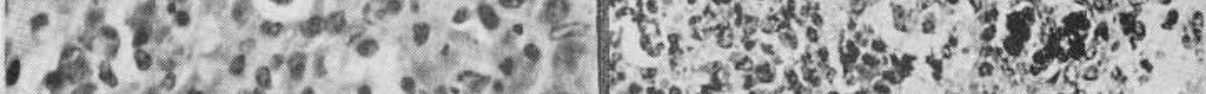

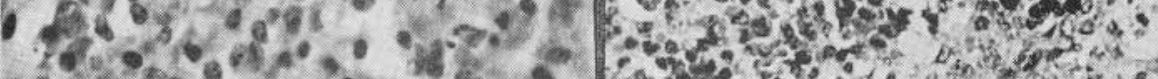

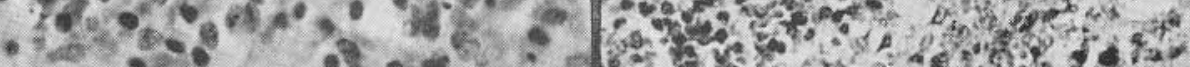

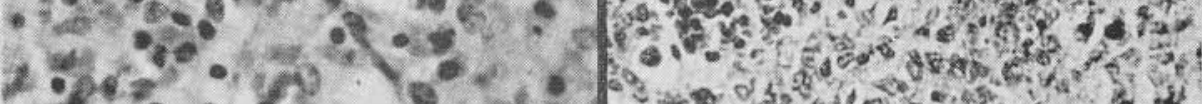

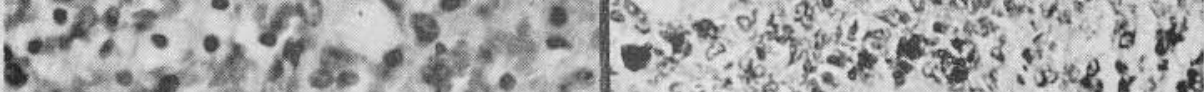

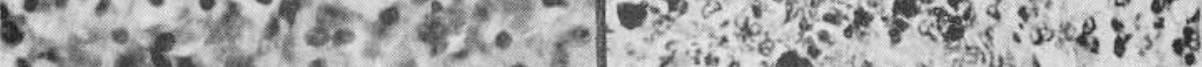

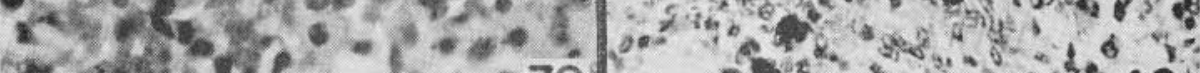

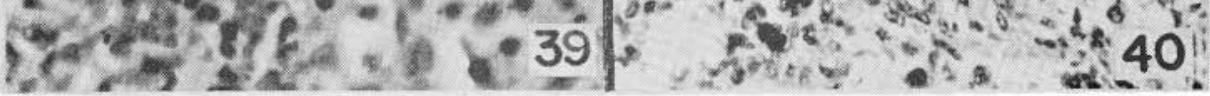


Fig. 41: Hígado: en la parte subcapsular, algunas zonas evolu cionan hacia la necrosis; nótese además la intensa reacción inflamatoria y la infiltración parasitaria (Col. hematoxilina-eosina; $300 \times)$.

Fig. 42: Higado: en la zona subcapsular, existen tres pequeños pseudoquistes (flechas) (Col. hematoxilina-eosina; 30()$\times)$.

Fig. 43: Pulmón: macrófago cuyo citoplasma está lleno de parásitos (flecha) en un tabique interalvéolar; véase la intensa reacción inflamatoria en estas zonas (Col. hematoxilina-eosina: $450 \times$ ).

Fig. 44: Aspecto que presentíron los pulmones de la rata $\mathrm{N}^{9} 4$; obsérvese los pequeños abscesos que ocupan la terceła parte del pulmón. 


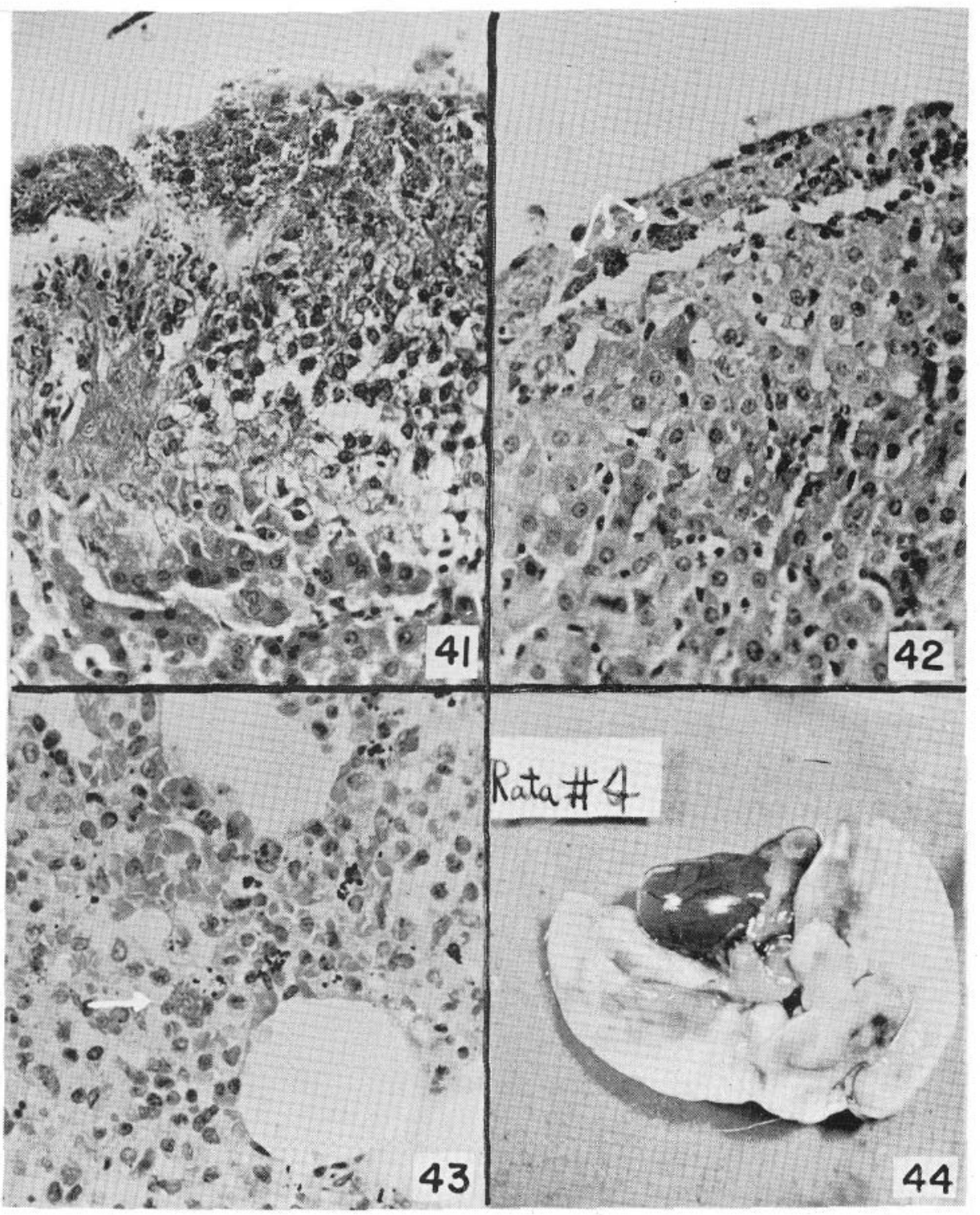

\section{$4 x^{2}+2$}

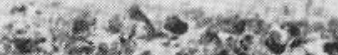

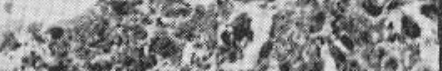

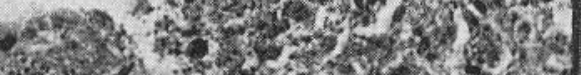

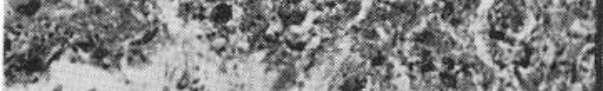

whis bit.

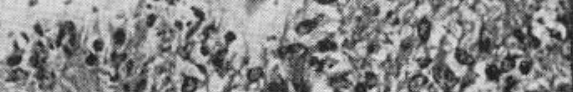
Hol

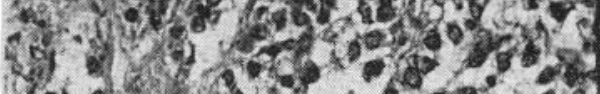

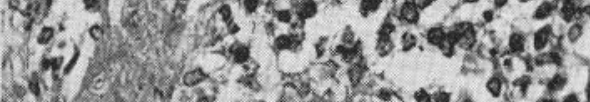

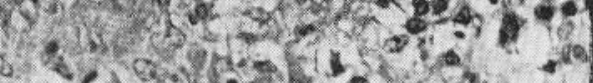

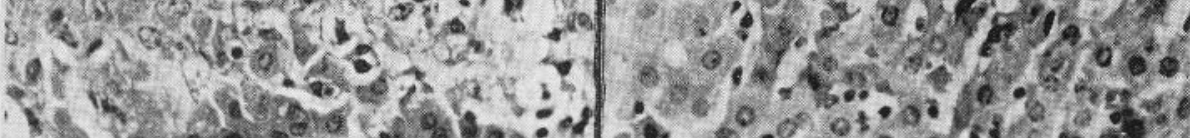

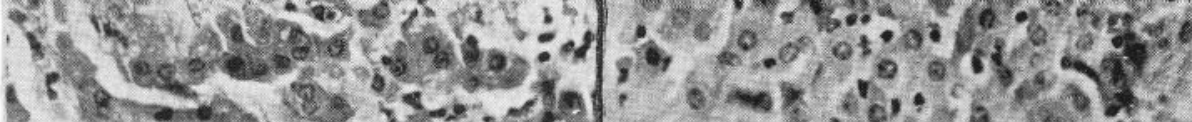

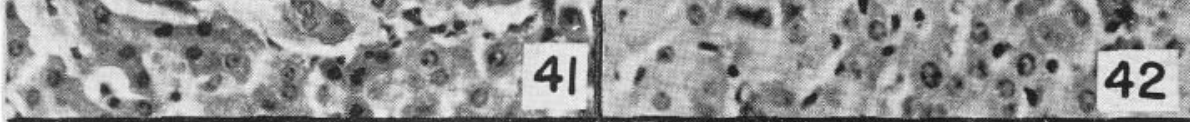

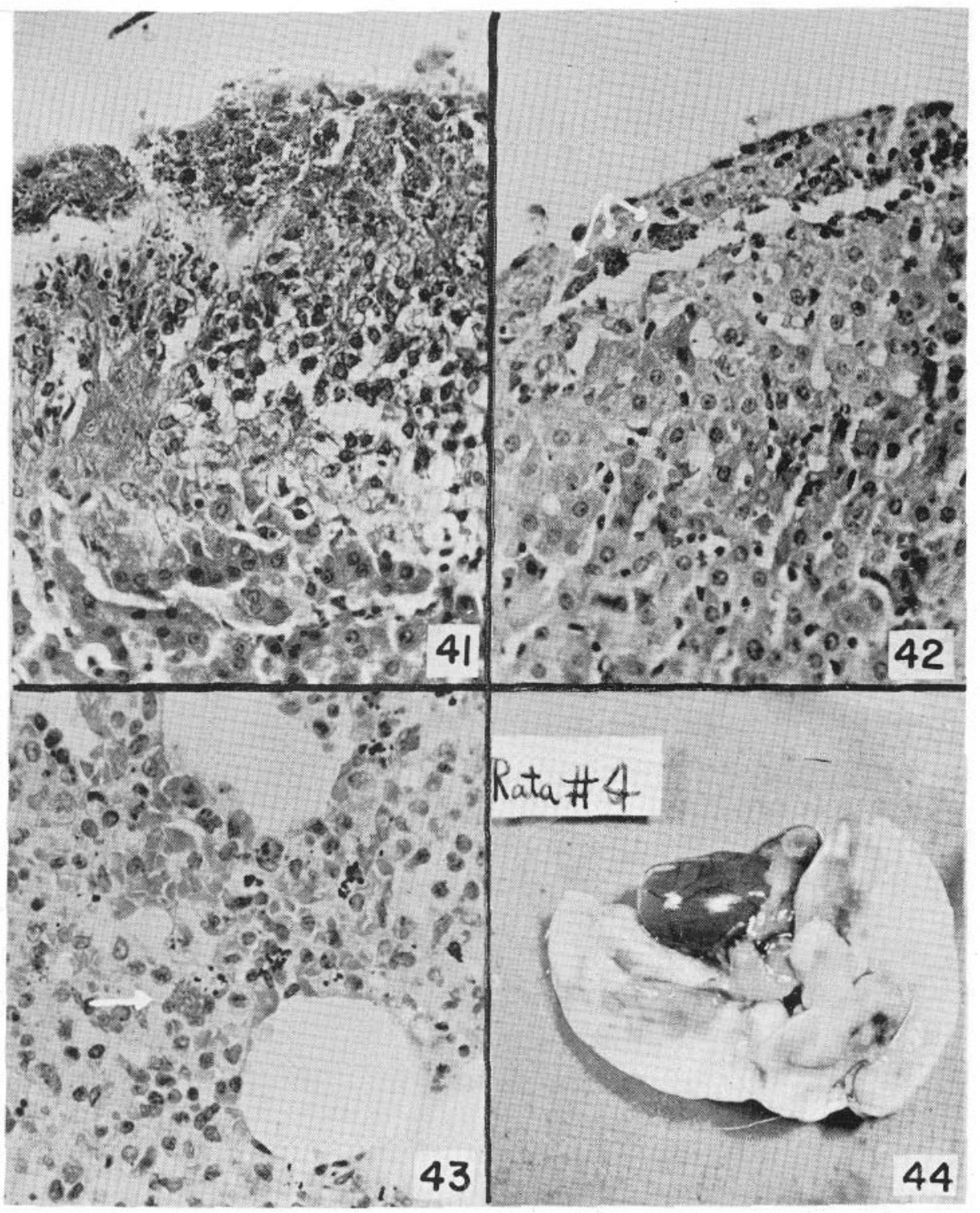

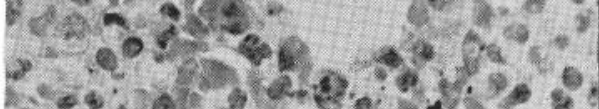

Conathecios?

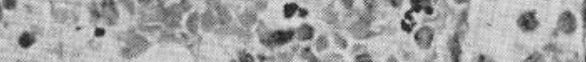

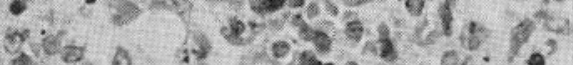

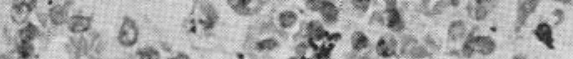

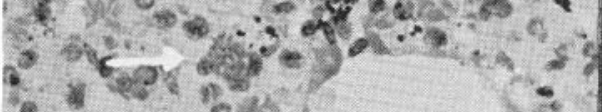

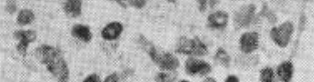

\&. as toses

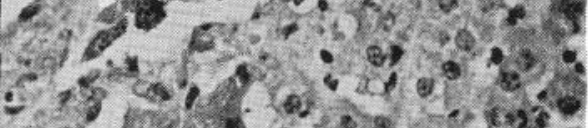

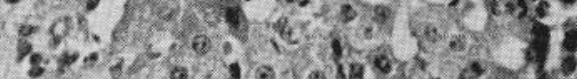

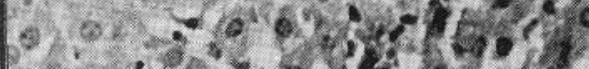

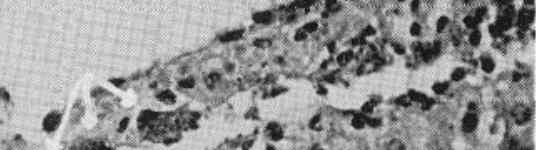

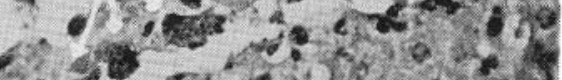


Fig. 45: Hígado: corte de un quiste subcapsular encontrado en el borde del hígado de la rata $N^{*} 4$, indentificado como Cysticercus fasciolaris; nótese la reacción predominantemente fibrosa en la vecindad (Col. hematoxilina-eosina; 2() $\times)$.

Fig. 46: Hígado: detalle de la figura anterior (Col. hematoxi. lina-eosina; $40 \times$ ).

Fig. 47: Pulmón: aspecto del exudado bronquial de los abscesos encontrados en la rata $N^{\prime \prime} 4$; la mayoría de los elementos que están en el bronquio son polimorfonucleares (Col, hematoxilina-eosina; $300 \times$ ).

Fig. 48: Pulmón: tejido de granulación formado alrededor del exudado purulento bronquial ( $\mathrm{Col}$. hematoxilina-eosina. $450 \times)$. 


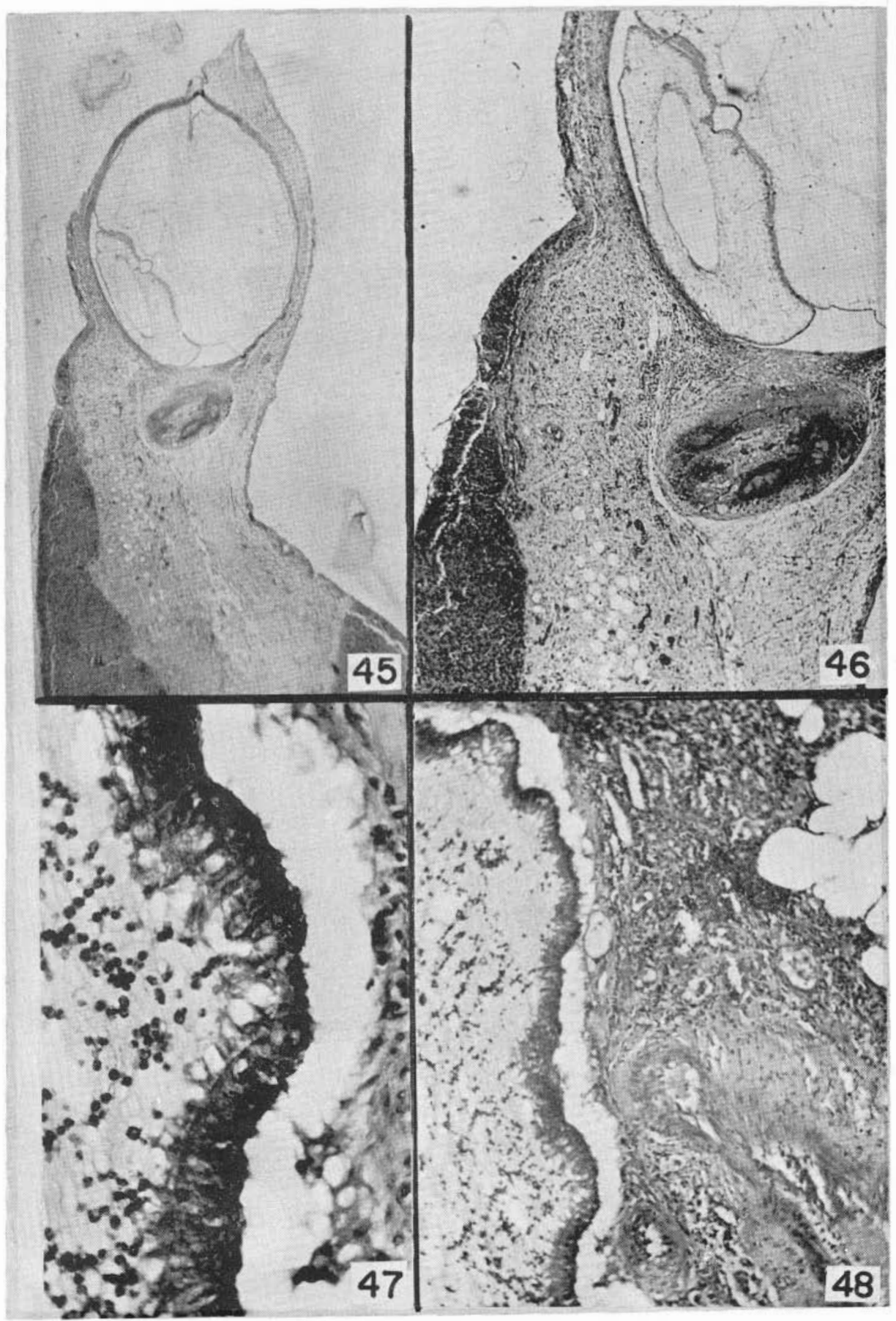

